\title{
Experiences of Parents of Children Adopted from Overseas: A Thematic Analysis of Narratives
}

\author{
Ekaterina Anatolyevna Amarando
}

Follow this and additional works at: https://researchrepository.wvu.edu/etd

\section{Recommended Citation}

Amarando, Ekaterina Anatolyevna, "Experiences of Parents of Children Adopted from Overseas: A Thematic Analysis of Narratives" (2016). Graduate Theses, Dissertations, and Problem Reports. 5093. https://researchrepository.wvu.edu/etd/5093

This Dissertation is protected by copyright and/or related rights. It has been brought to you by the The Research Repository @ WVU with permission from the rights-holder(s). You are free to use this Dissertation in any way that is permitted by the copyright and related rights legislation that applies to your use. For other uses you must obtain permission from the rights-holder(s) directly, unless additional rights are indicated by a Creative Commons license in the record and/ or on the work itself. This Dissertation has been accepted for inclusion in WVU Graduate Theses, Dissertations, and Problem Reports collection by an authorized administrator of The Research Repository @ WVU.

For more information, please contact researchrepository@mail.wvu.edu. 
Experiences of Parents of Children Adopted from Overseas: A Thematic Analysis of Narratives

Ekaterina Anatolyevna Amarando

Dissertation submitted to the College of Education and Human Services

at West Virginia University in partial fulfillment of the requirements

for the degree of

Doctor of Philosophy

in

Counseling Psychology

Jeffrey Daniels, Ph.D., Chair

James Bartee, Ph.D.

Christine Schimmel, Ed.D

Lisa Hamilton. Ph.D.

Melissa Sherfinski, Ph.D.

Department of Counseling, Rehabilitation Counseling, and Counseling Psychology

Morgantown, West Virginia

2016

Keywords: International adoption; Parental adjustment; Transracial adoption; Attachment Copyright 2016 Ekaterina Amarando 


\begin{abstract}
Experiences of Parents of Children Adopted from Overseas: A Thematic Analysis of Narratives Ekaterina Anatolyevna Amarando

Parents from the United States adopt more children from overseas than parents from any other country. There are numerous factors that play a role in the decision to adopt internationally, and most families remain highly satisfied with the adoption outcome (Adoption Institute, 2010). However, families with internationally adopted children face numerous challenges during their adoption journey, and generally report a higher utilization of professional services than biological families (Adoption Institute, 2010). In this study I utilized a qualitative research design to examine experiences of parents who adopted children from other countries. Thematic analysis of family narratives was employed to examine the stories of parents and identify their current needs. It was found that themes of loss, anticipation, and emotion-focused coping prevail in the adoptive families' narratives. Clinical implications, strengths and limitations, and recommendations for mental health professionals who work with adoptive families are discussed.
\end{abstract}




\section{Acknowledgments}

I am grateful for the support of my advisor, Dr. Jeffrey Daniels, whose help and guidance I could always count on during this journey. Many thanks to my committee: Dr. James Bartee, Dr. Christine Schimmel, Dr. Melissa Sherfinski, and Dr. Lisa Hamilton. It has been a privilege to have you on my team and I truly appreciate your support.

Thanks to all the participants who agreed to share their stories with me. It was an inspiring and humbling experience, and I am honored to be a part of that.

And of course, I could not have done it without the love and support of my family. I am forever grateful to my parents and my son who have been there for me every step of the way. Thank you and I love you always. 


\section{Table of Contents}

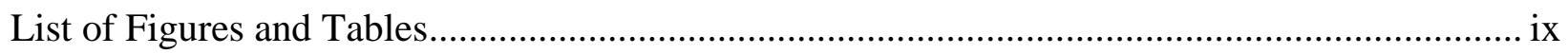

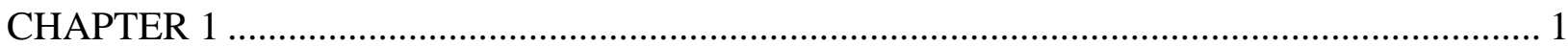

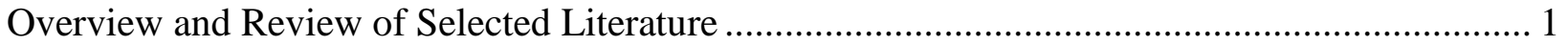

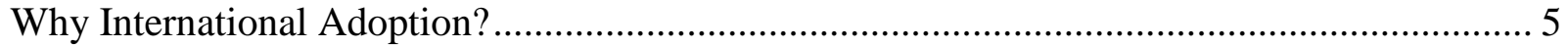

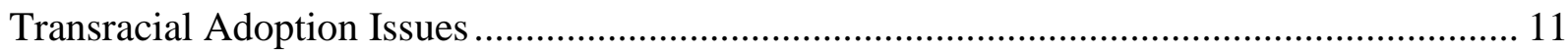

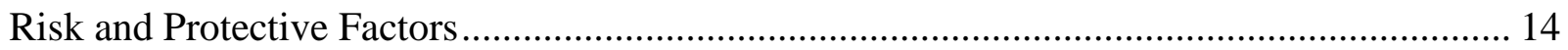

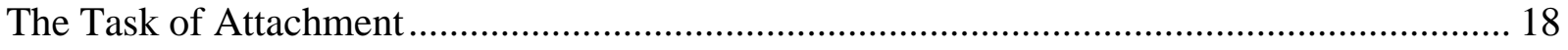

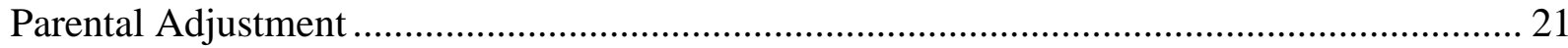

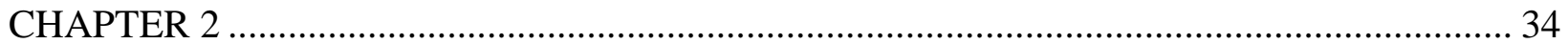

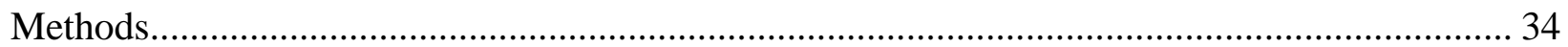

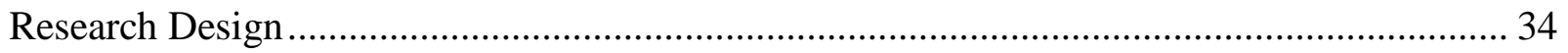

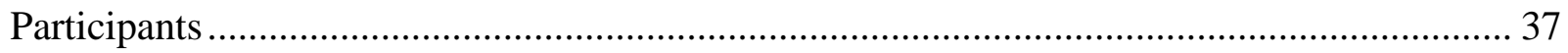

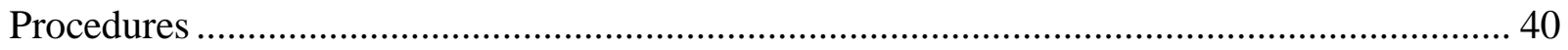

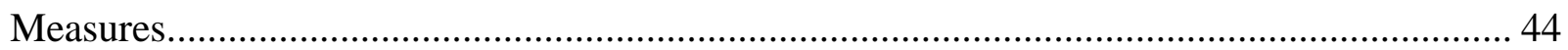

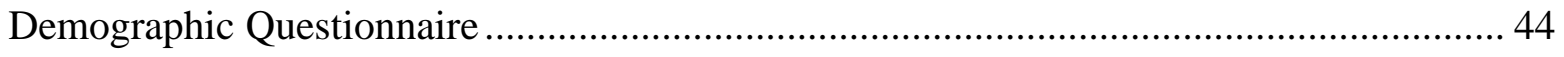

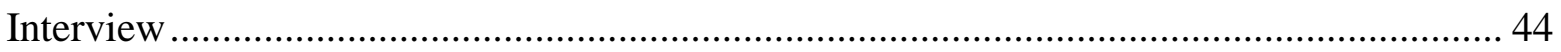

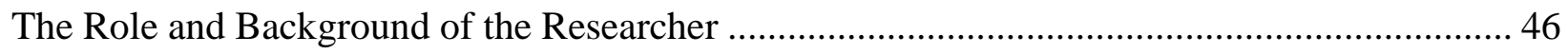

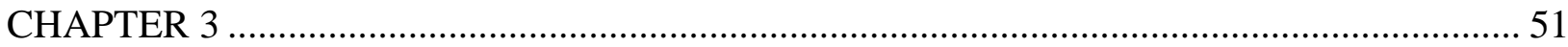

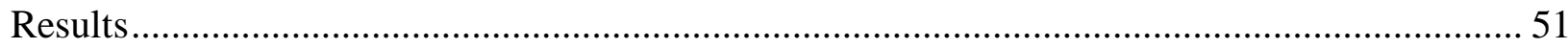




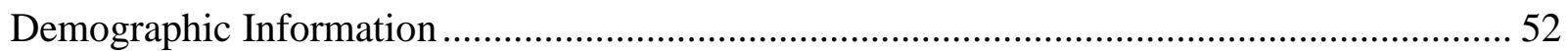

How Did You Come to a Decision to Adopt a Child from Another Country?....................... 56

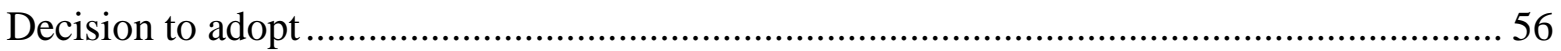

International versus domestic adoption ................................................................. 57

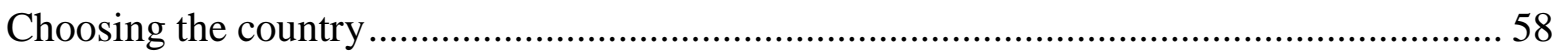

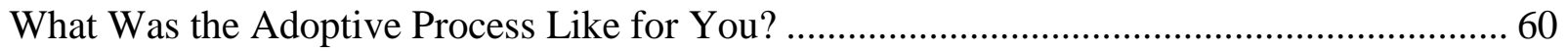

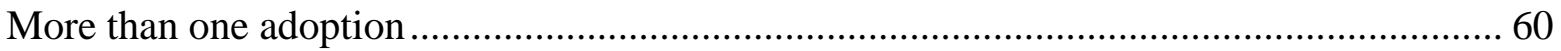

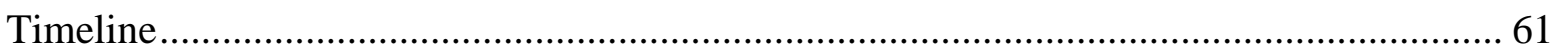

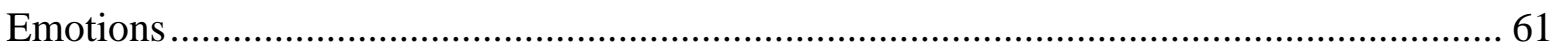

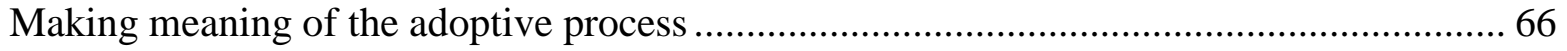

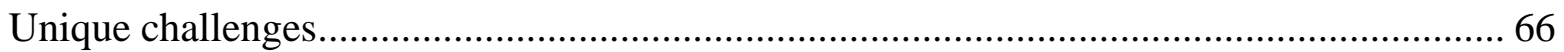

Please Describe the First Few Months with the Newly Adopted Child............................... 67

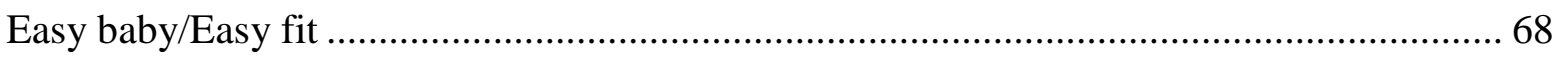

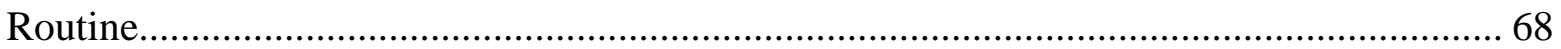

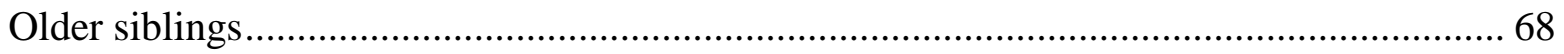

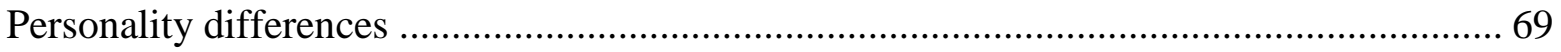

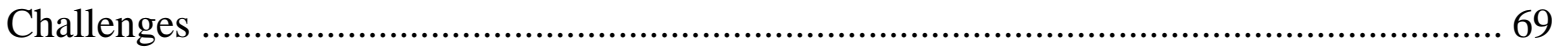

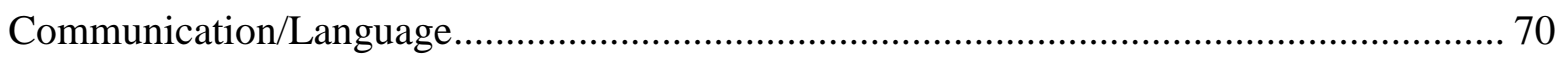

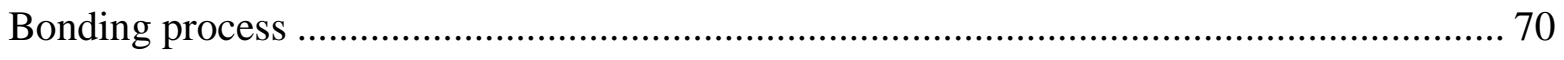

How Did the Child Fit with Your Nuclear Family and the Extended Family?...................... 73 


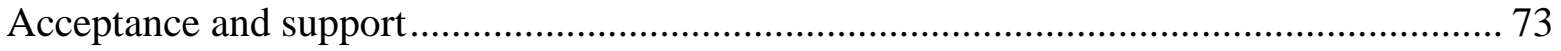

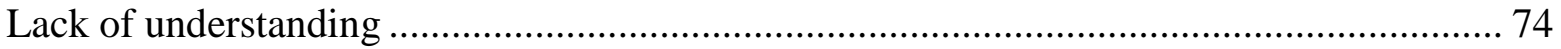

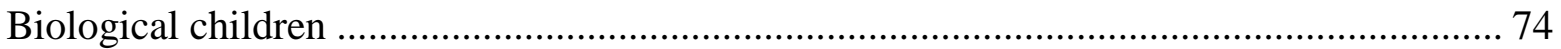

Have You Experienced Any Issues in Regard to Your Child's Ethnic or Racial Background?

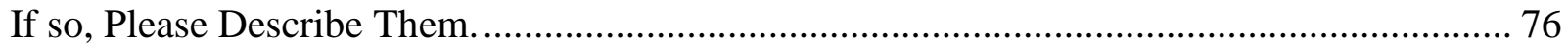

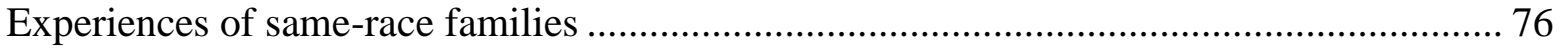

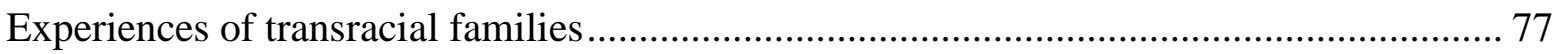

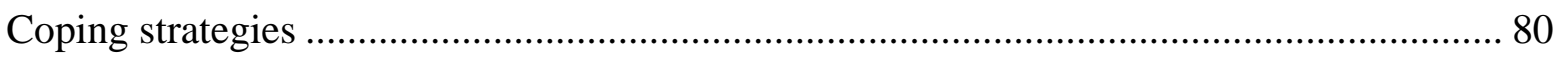

What Were the Supports and Other Resources Available to You in Your Adoption Journey? 82

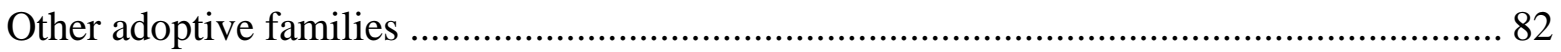

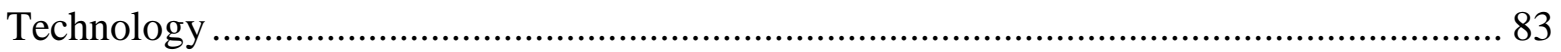

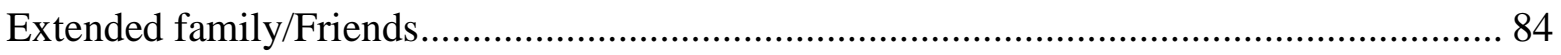

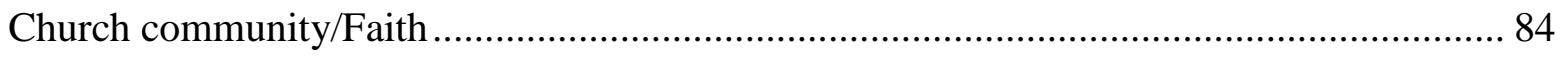

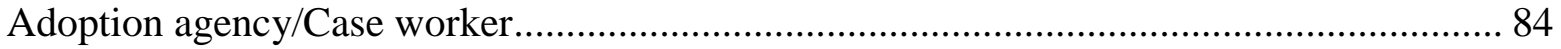

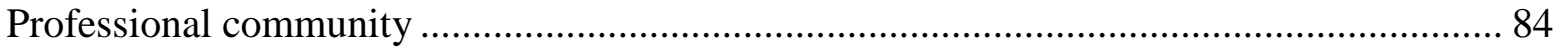

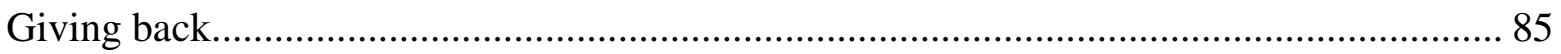

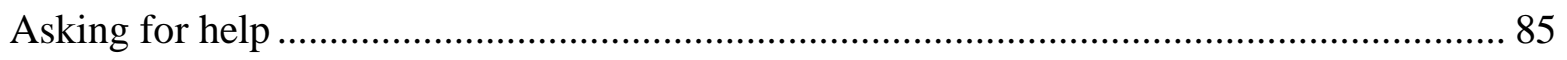

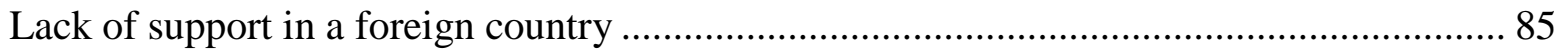

How Can the Services in the Professional Community Meet Your Needs Better? ................. 86

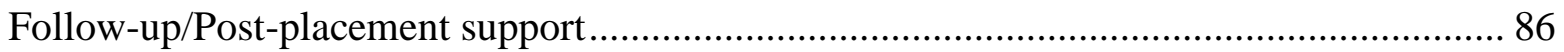




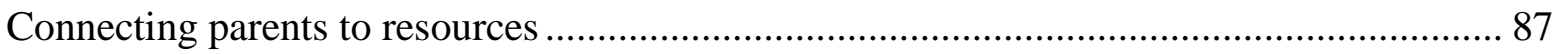

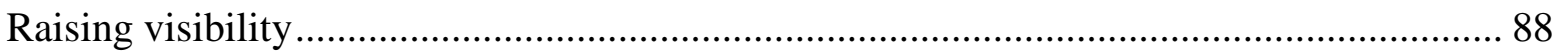

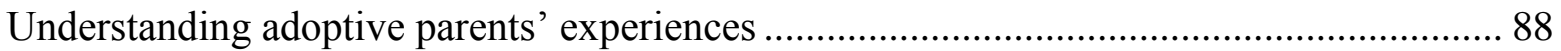

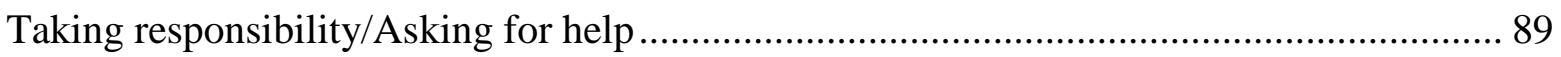

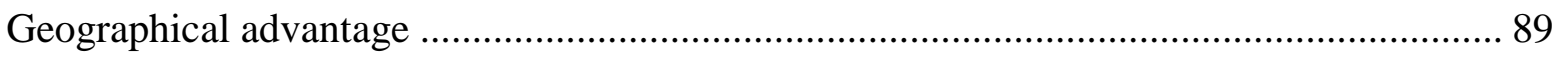

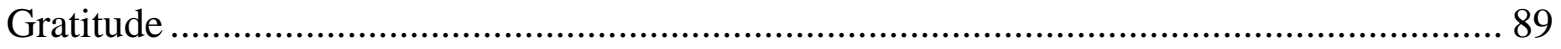

What Would Be One Sentence/Word Summary that Describes Your Entire Adoption Journey?

Is There Anything Else that You Feel Is Important to Mention?......................................... 90

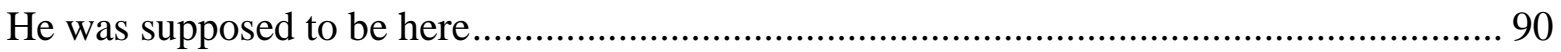

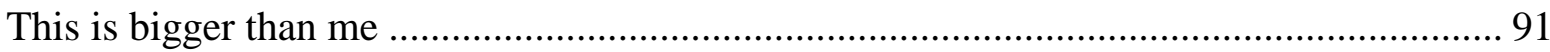

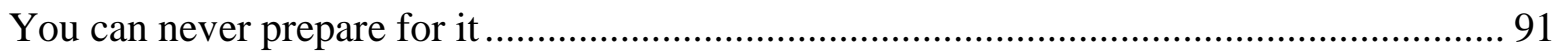

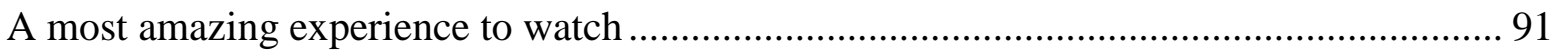

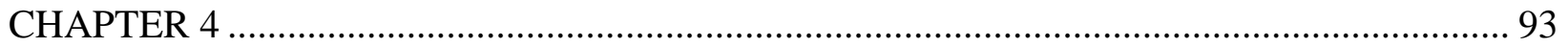

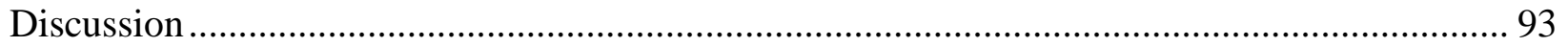

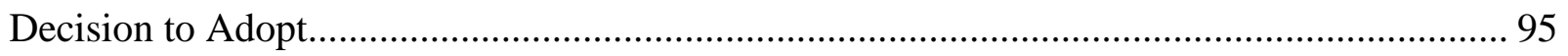

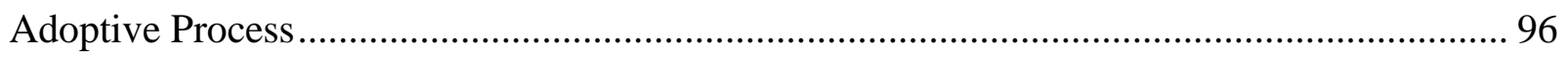

The First Few Months with the Child .......................................................................... 99

Fit with the Extended Family ............................................................................... 101

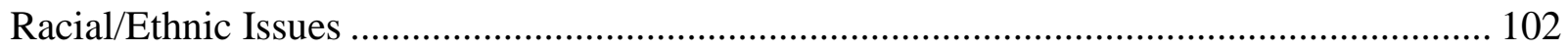




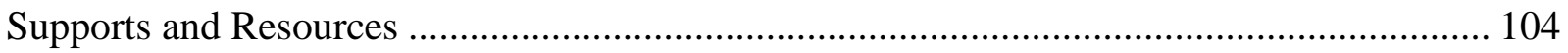

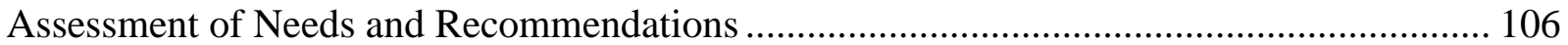

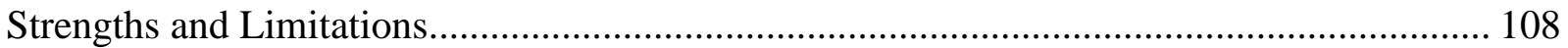

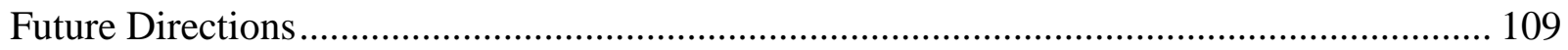

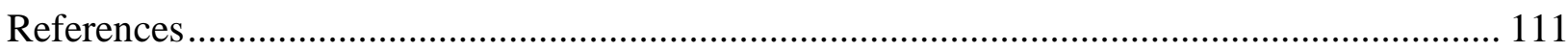

APPENDIX

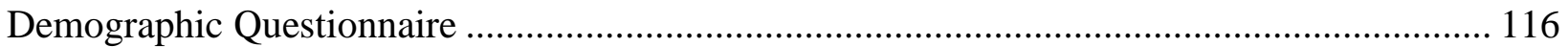




\section{List of Figures and Tables}

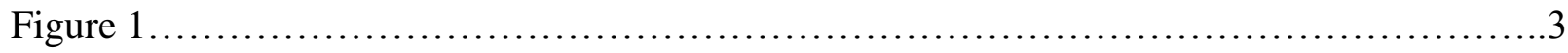

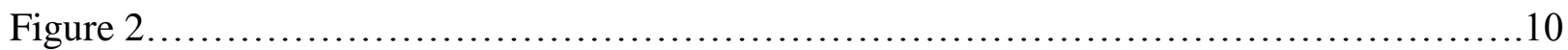

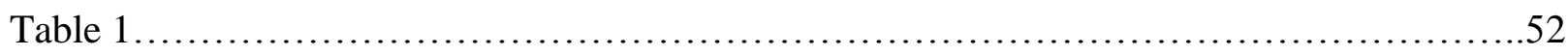

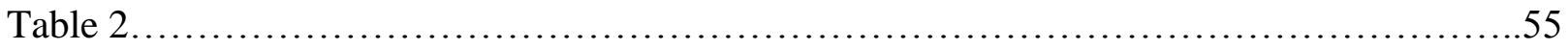




\section{CHAPTER 1}

\section{Overview and Review of Selected Literature}

Adoption is a process that changes lives of everybody involved. Whether it is a

domestic, international, private, or foster care adoption, for over $90 \%$ of the families it remains a highly positive experience as most parents report being satisfied with their adoption outcomes (Adoption Institute, 2010). Numerous studies have shown that being raised in an adoptive home leads to a better life adjustment of adoptees than being raised in an institution or foster care (Adoption Institute, 2010). Meanwhile, the adoption journey is often arduous and full of setbacks. Adoptive families and their children are overrepresented in clinical populations, with manifestation of behavioral and emotional problems, learning disabilities and substance abuse issues (Adoption Institute, 2010). However, despite the challenges that adoptive families may encounter during the adoptee's childhood and adolescence, the longitudinal research shows that most adopted children eventually catch up with biological children and become fully functioning adults (Barth, Crea, John, Thoburn \& Quinton, 2005). Benefits of adoption clearly outweigh the challenges that adoptive families face, and their journey can be best described as a "meandering and thorny path to a relatively normal adulthood" (Barth et al., 2005, p. 262).

According to Hellerstedt, Madsen, Gunnar, Grotevant, Lee and Johnson (2008), approximately $20 \%$ of all children adopted in the U.S. were adopted from other countries. American parents adopt more children from overseas than any other nation (Voigt \& Brown, 2013). In 2012, there were 8,668 U.S. families that adopted children from other countries (United States Department of State, 2013). Among the top three countries from which American parents adopted their children in 2012 were China (2,697), Ethiopia $(1,568)$, and Russia $(748)$ (United States Department of State, 2012). The number of American parents adopting children 
from other countries rose steadily until 2004 when international adoptions began declining. According to the experts, this decline is not due to a reduction of parents wanting to adopt from abroad, nor is it due to fewer children available for adoption (Voigt \& Brown, 2013). Rather, it is the result of stricter regulations and a growing attitude against placing children in international families by such popular sending countries as China and Russia. In fact, after a much heated debate in December 2012, the Russian government closed its borders to American parents wanting to adopt Russian children effective January 1, 2013 (CNN Staff, 2012). Prior to that, China implemented stringent rules regarding the adoption of Chinese infants by foreigners. Some of the exclusion criteria for adopting a healthy infant from China are: being single, being over 50 years old, being morbidly obese, being blind, and having facial deformities or severe mental illness, among the few (Voigt \& Brown, 2013). Older children with special needs are easier to obtain; however, the demand for healthy young children is much greater. For various other reasons, adoption programs have closed in several other countries, such as Guatemala, Ghana, Nepal, and Vietnam in the recent years. Despite thousands of available orphans worldwide and many American families wanting to adopt, international adoptions are becoming increasingly more difficult for prospective adoptive parents, creating uncertainty and emotional distress for them. Figure 1 illustrates the number of international adoptions by U.S. parents from the years 2000 to 2012 . 
Figure 1. Total Number of International Adoptions in the U.S. (from United States Department of State, 2012).

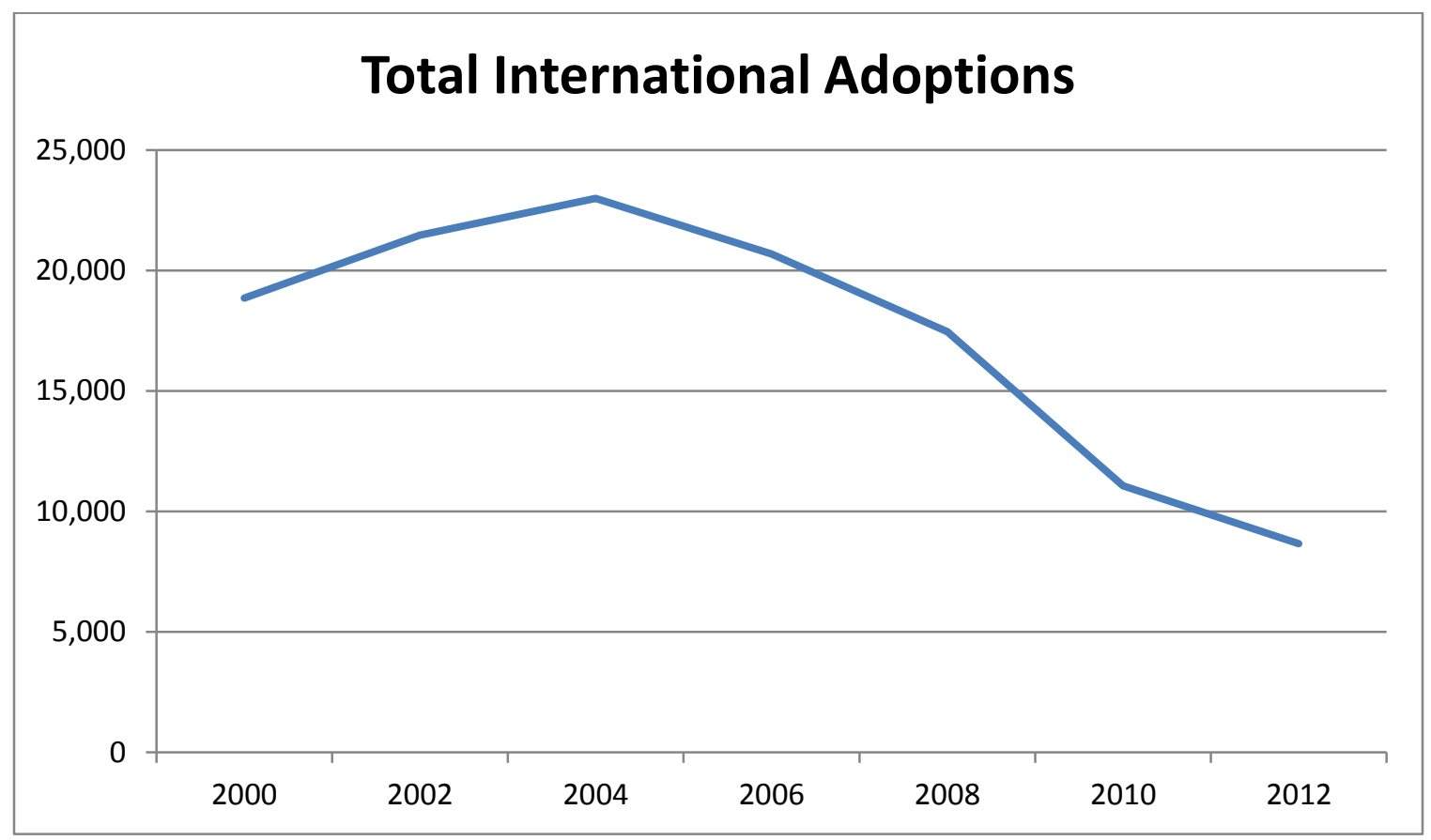

Despite the recent decline, however, there were 242,602 finalized international adoptions in the years 1999-2012 which means that almost a quarter of a million children raised by families in the U.S. have been adopted from other countries (United States Department of State, 2012). Little is known about these families, however. Adjustment of international adoptees has received considerable interest from researchers studying attachment and early childhood experiences (Shapiro, Shapiro, \& Paret, 2001; Stams, Juffer, \& van IJzendoorn, 2002; van Londen, Juffer, \& van IJzendoorn, 2007; Welsh, Viana, Petrill, \& Mathias, 2007), but there is a dearth of studies focusing on adoptive parents and their psychological adjustment. This is an important issue for researchers to consider because adoptive families are three times more likely to seek clinical services than birth families (Adoption Institute, 2010). According to the Evan B. Donaldson Adoption Institute (2010), the 2007 National Survey of Adoptive Parents showed that families with children from other countries have the highest utilization of supportive services. It 
is obvious that there is a high demand for professional help among families who adopt international children and a great need for empirically supported interventions for this population.

In order to develop these interventions, it is important to assess the specific mental health needs that international adoptive families exhibit. Qualitative inquiry into the parents' experiences with international adoption will allow for a deeper understanding of internal processes associated with this complex phenomenon. Thus, the research questions that will be addressed in this study are the following:

1. How is the process of international adoption experienced by the adoptive parents?

2. Are there common themes associated with psychological adjustment for parents who adopted children from overseas, and if there are, what are these themes?

3. What are the needs of families with children adopted from overseas?

Since the goal of this study is to uncover unique experiences of adoptive parents, qualitative research would be the most appropriate design due to its emphasis on studying "individuals who have firsthand knowledge of the phenomenon of interest" (Friedlander, Larney, Skau, Hotaling \& Schwam, 2000, p. 189). Among different qualitative approaches, thematic analysis with elements of narrative inquiry was chosen as the most suitable method because it allows researchers to uncover unique experiences of the participants through their stories (Josselson, 2011). The findings of this study will greatly benefit understanding of psychological processes that occur in the adoptive family dynamics and identify the needs of adoptive families after international adoption. This will in turn facilitate the development of empirically informed interventions that can be utilized by mental health professionals during their work with adoptive families. 
To avoid any confusion about the terminology pertaining to international adoption, the most commonly used terms are defined in this paragraph. In this paper, international (also transnational or intercountry) adoption refers to the adoption of a foreign-born child by American parents whereas domestic adoption refers to the adoption of a U.S. child by U.S. parents. Countries from which parents choose to adopt are commonly referred to as "sending countries," and countries into which children are adopted are referred to as "receiving countries." Transracial adoption refers to the phenomenon in which adoptive parents and their children do not share the racial phenotype. In other words, it is the "visible" adoption, resulting in a family with members who are visibly different from each other. Additionally, it is important to distinguish the terms "biological" and "adoptive." The term "biological parents" refers to parents who gave birth to the child, whereas "adoptive parents" refers to parents who adopted the child.

\section{Why International Adoption?}

According to Hogbacka (2008), intercountry adoption in its present form began after the Second World War as a humanitarian effort to rescue children orphaned by the war. This phenomenon became more widespread during the 1960s as the number of infants available for domestic adoptions decreased as a result of changing attitudes toward single motherhood, wider availability of contraceptives, and changes in abortion practices (Hogbacka, 2008). However, the most notable increase in intercountry adoptions occurred in the 1990s when the one-child policy in China produced many abandoned children, and the Soviet Union opened its borders (Voigt \& Brown, 2013). Since then, international adoptions in the United States have been steadily increasing until 2004 when regulations and policies in the major sending countries became more stringent and adoptions started declining (Voigt \& Brown, 2013). There are 
various factors that affect this phenomenon, with the main four listed as "war, imbalance in socioeconomic conditions between the sending and receiving countries, organizational linkages between them, and a political decision in the sending country to allow intercountry adoptions" (Hogbacka, 2008, p. 313). Other influences include policies that limit women's reproductive rights, poverty, and lack of support systems for poor families and single mothers (Hogbacka, 2008). Overall, policies of sending countries play a significant role in the supply of children available for adoption. These policies are also responsible for the decline in international adoptions in the recent years.

There are different reasons why people choose to become parents through adoption, and these reasons vary across individuals. The predominant motivating factor to adopt among the majority of individuals, however, is infertility (Young, 2012). Infertility resulting from delayed childbearing is increasing all over the developed world, and most people who are looking to adopt are involuntarily childless (Hogbacka, 2008). According to the studies of Australian adoptive parents and Finnish infertility doctors reviewed by Hogbacka (2008), there was a hierarchy of preferences in regard to having children. These studies found that the most desired scenario for the parents was to have a biological child, followed by a child born with the assistance of reproductive technology. If that was not possible, domestic adoption was the next preferable option, and international adoption was considered last by the adoptive parents. The child's characteristics also played an important role in the adoptive process, with healthy young infants being the most desirable and older children or special needs children the least desirable. In regard to gender, girls were generally more preferred than boys by adoptive parents (Hogbacka, 2008). Additionally, these studies indicated that ethnic characteristics contributed to the hierarchy (Hogbacka, 2008). In their wish to have children who look as similar to them as 
possible, adoptive parents from receiving countries generally prefer children with white skin color, with Asian or Latin American looks being the next preferred option, and darker skin color at the bottom of the list (Hogbacka, 2008).

To summarize, adoption often comes secondary to having biological children. By the time many individuals or couples arrive at the decision to adopt a child, it is not uncommon for them to have tried to conceive without success and to have gone through various infertility treatments. This process usually leaves the parents emotionally and financially drained. The decision to adopt a child from another country, therefore, is a result of complex internal processes and motivating factors. So what does the scientific community know about American parents who turn to international adoption, and is the demographic profile of adoptive families that come together as a result of transnational adoption different than an average American family?

According to Pryor and Pettinelli (2011), the most common reasons that parents choose intercountry adoption over domestic adoption are declining numbers of infants available to adopt domestically, a risk that birth parents will reclaim the child after a domestic adoption, and the increase of media attention to the plight of orphans overseas. Other reasons reported in a study of Australian parents who adopted children from other countries included altruism, shorter time frame for intercountry adoptions, and no continued contact with birth parents (Young, 2012). In addition to that, Australian parents reported that they chose international adoption because the children available domestically from foster care are usually older and have an extensive history of trauma. A population-based study of Minnesota adoptive parents provided further insights into why parents chose to adopt from overseas, including an increased certainty that birth parents will not claim the child back, a greater availability of white infants via international adoption 
than via domestic adoption, a fear of adopting a domestic child who may have special needs, the U.S. adoption policies that make domestic interracial adoptions difficult, and an easier adoption process for non-traditional families, such as same-sex and single parent families (Hellerstedt, et al., 2008). To summarize, most families choose to adopt as a result of infertility, and some families find international adoption more appealing than domestic adoption due to a greater availability of healthy infants, shorter waiting times, and a greater certainty that the child will not be reclaimed by the birth parents.

In one of the most comprehensive studies in this area, Hellerstedt et al. (2008) conducted the first population-based surveillance of U.S. parents who adopted non-U.S. children. Their International Adoption Project encompassed 1,834 Minnesota parents who adopted children from other countries between 1990 and 1998 (Hellerstedt et al., 2008). They found that 97\% of these families identified as White/Caucasian prior to adoption, and $88 \%$ of these families became transracial after adoption. Only $15 \%$ of these families had household income of less than $\$ 50,000$, and $70 \%$ of parents had at least a college degree, with $30 \%$ holding a postBaccalaureate degree. Eighty six percent of families were married at the time of survey, and although the ages of parents ranged between 23 and 65 years old, the average parental age at the time of the child's placement was 38 years old. Thus, the demographic profile of parents who adopt children from abroad is different from the demographics of U.S. families with biological children because these adoptive parents are generally older, more financially secure, predominantly white, college-educated, and are more likely to be married. Although this profile is generally comparable with the profile of parents who adopt domestically, the authors discovered that families with internationally adopted children are more likely to have a higher socioeconomic status than families with children adopted from the U.S., which is expected given 
the prohibitive cost of international adoptions and the lack of public assistance for them (Hellerstedt et al., 2008).

According to the United States Department of State, the top sending countries in 2012 were China, Ethiopia, Russia, South Korea and Ukraine (2012). Further examination reveals that between the years of 1999 and 2012 Americans adopted children from all over the world, with $29 \%$ of all adoptees coming from China, $19 \%$ from Russia, $12 \%$ from Guatemala, $8 \%$ from South Korea, and 5\% from Ethiopia. Ukraine, Kazakhstan, and India come next, with 4\%, 3\%, and $2 \%$ of adopted children, respectively (U.S. Department of State, 2012). According to Zhang, nearly six out of ten intercountry adoptees are adopted from Asia (2010). Additionally, the U.S. data from 1999 to 2012 show that the gender of adoptees varied depending on the sending country, with $90 \%$ of children from China being female, $59 \%$ of children from South Korea being male, and an even distribution of 50/50 of both genders from Russia. Overall, 58\% of children adopted by American parents during the past 13 years from all over the world were female, according to the U.S. Government statistics (U.S. Department of State, 2012).

Although the ages of children at the time of adoption vary, statistics for the past 13 years provided by the U.S. Department of State show that approximately $71 \%$ of children were younger than two years old when they were adopted (2012). Their ages are further distributed in the following way: $38 \%$ were under one year old, $33 \%$ were between one and two years old, $8 \%$ were between three and four years, $11 \%$ were five to 12 years of age, and $2 \%$ were between 13 17 years old. Please see Figure 2 for the illustration of ages at the time of adoption. 
Figure 2. Ages at the Time of Adoption (from the United States Department of State, 2012).

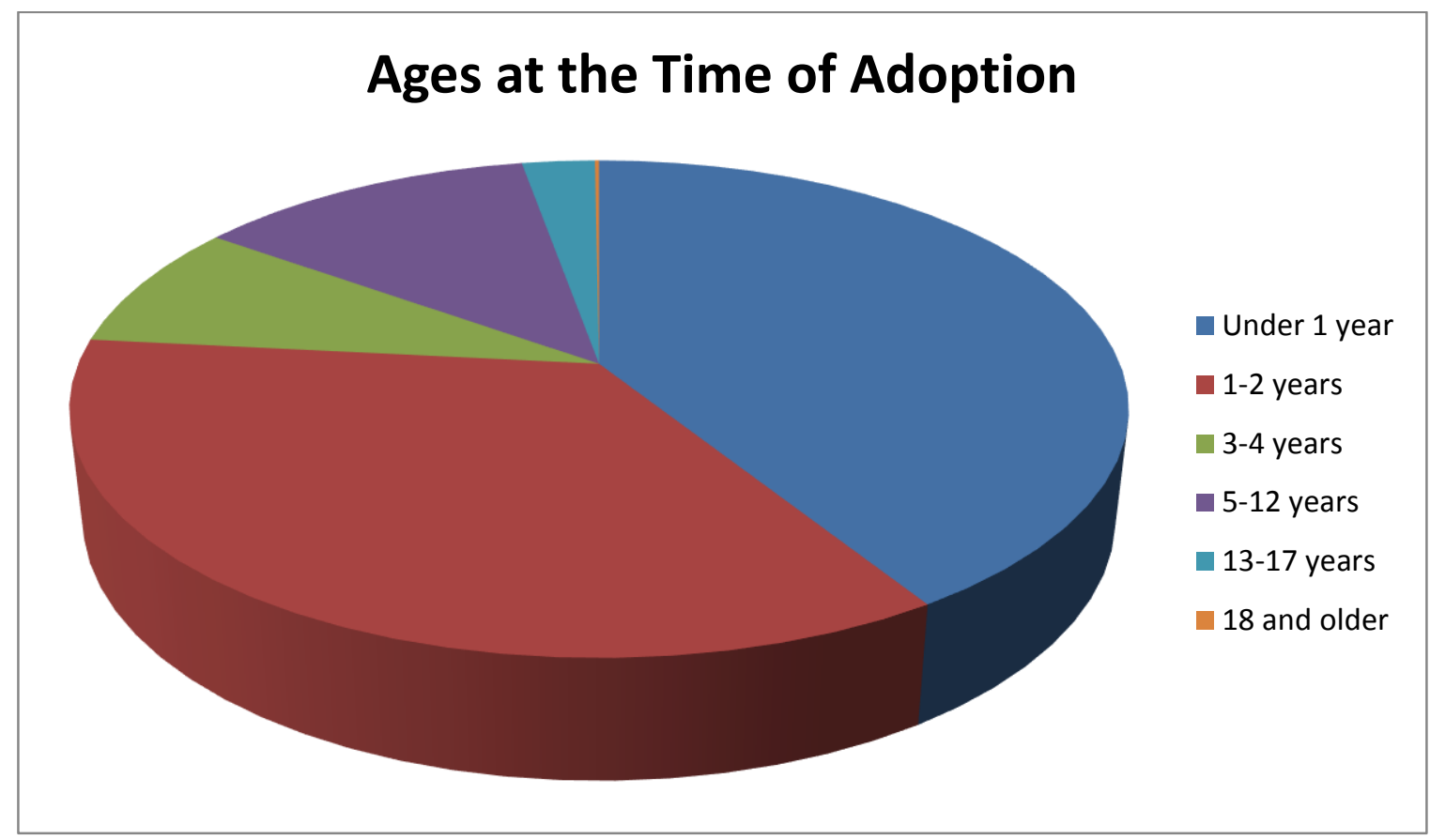

Additionally, Hawk and McCall (2010) estimated that about $85 \%$ of children adopted from other countries have spent some time in institutions. The negative effects of institutionalization have been widely documented in the literature, and some researchers consider international adoptees an "at risk" population (Viana \& Welsh, 2010). More discussion on institutional rearing will follow in the Risk and Protective Factors section of this dissertation.

To summarize, most children adopted from other countries are likely to be under two years old at the time of adoption, belong to a different race than their adoptive parents, and have spent some time in an institution. There were slightly more girls than boys adopted by the American parents in the past 13 years, with China sending girls $90 \%$ of the time. As Hellerstedt et al. pointed out, $88 \%$ of U.S. families became transracial as a result of international adoption. Transracial adoptive families have been a subject of continued interest for researchers who study racial identity formation and psychological adjustment of transracial adoptees. There is limited data, however, on psychological adjustment of adoptive parents and their experiences with 
transracial issues. In the next section the existing research on issues that arise as a result of transracial adoptions and their impact on adoptive families will be summarized.

\section{Transracial Adoption Issues}

Given the racial differences between most intercountry adoptees and their U.S. parents, it is important to address the issues associated with transracial family formation. Lee, Grotevant, Hellerstedt, Gunnar and the Minnesota International Adoption Project Team noted that transracial adoptees are more likely to struggle with racial and ethnic issues than same-race adoptees (2006). Zhang reported that "compared to non-transracial adoptees, transracial adoptees place more importance on their own racial identity than their adoptive identity" (2010, p.174). Some adoptees may assume the racial identity of a parent but will be seen by the society as individuals of their own racial phenotype, resulting in a transracial adoption paradox - an internal conflict and confusion regarding self-identity of a transracial adoptee (Zhang, 2010). Additionally, Hellerstedt et al. reported that "families that are formed through international adoption thus may face specific challenges associated with the apparently opposite goals of acculturation and maintenance of cultural identity that could influence later psychological, physical, and social health" (2008, p. 169). Teasing and racial discrimination may also occur for children from transracial adoptive families (Hellerstedt et al., 2008).

Zhang noted that the main issues that transracial intercountry adoptees face are racial identity formation, reconnections with the adoptee's native home and culture, and coping with discrimination and stereotyping (2010). This undoubtedly has an impact on their adoptive parents as they must learn how to improve their child's adjustment as well as to determine the extent of involvement in the child's cultural heritage. Thus, racial and cultural socialization of transracial children is an important task for the parents to navigate. However, as members of the 
white majority, many adoptive parents are not prepared to deal with transracial issues due to their lack of direct experience with these problems. Moreover, they may lack understanding or be in denial that these issues exist. This general unawareness or denial of racial differences and racial discrimination in the society is referred to as the color-blind racial attitude (Lee et al., 2006).

Currently views on color blindness in transracial family adjustment remain highly

polarized. Proponents of the colorblind adoption model argue that it manifests racial integration and awareness, as well as erase racial barriers (Zhang, 2010). However, the racial dynamics in the U.S. society are not as linear. Zhang argued that "many intercountry adoptees are at risk to assume a White racial identity and adopt the White-majority culture" perpetuating "the parents' cultural and racial outlook" (2010, p. 173). Some adoptive parents are not aware of the potential threat of racist attitudes and do not sufficiently prepare their transracial children to cope with the racial bias that exists in the society (Hellerstedt et al., 2008; Zhang, 2010). Other challenges that adoptive parents may face in their effort to instill a healthy racial and cultural identity of a child are the lack of knowledge of the child's culture and superficial or misguided efforts to expose the child to it, difficulty finding resources or information on identity development and coping with discrimination, limited opportunities for their children to interact with same-race groups, and, in some cases, exoticizing the child and treating him or her like an "ethnic doll" (Zhang, 2010, p. 177).

Despite the challenges, Lee et al. (2006) found that adoptive parents engaged in a variety of cultural socialization behaviors in an attempt to transmit the child's heritage by exposing him or her to the birth culture values, beliefs, customs, and traditions. They found that $83 \%$ of children participated in at least one cultural activity within the previous year, with an average of three such activities. Interestingly, children from Russia and Eastern Europe participated in 
fewer cultural activities than children from China, Colombia, Korea, India, and Southeast Asia (Lee et al., 2006). This may be due to the fact that children from Russia and Eastern Europe are more likely to be of the same race as their adoptive parents, and it supports the idea that transracial adoptive parents are more sensitive to cultural socialization issues than parents with children of the same race. Another finding was that the majority of parents (78\%) reported that they spoke with their child about racism and discrimination (Lee et al., 2006). Overall, Lee et al. found that parents scored lower on color-blind racial attitudes and higher on enculturation and racialization beliefs, meaning that they were more likely to believe that it is important to make the child aware of racism and discrimination and promote the child's ethnic knowledge, pride, values, and behaviors (2006). The authors also found that consistent with such beliefs, adoptive parents participated in various cultural activities and discussed racism and discrimination with their children (Lee et al., 2006).

Another study examined the influence of inappropriate outsider remarks on the identity of transracial adoptive families (Sutter \& Ballard, 2009). According to the authors, visible differences between the family members often provoke outsider remarks and questions that range from idle curiosity to negative judgments, such as "How much did you pay for her?", "What a China doll", and "Who is the real mother?" (Sutter \& Ballard, 2009, pp. 120-121). Sutter and Ballard found that despite insensitive, racist, or invasive outsider comments, adoptive parents were able to produce identity-affirming responses to preserve their family identity (2009). According to them, parents chose their responses based on the context, and these responses ranged from dismissal to disclosure. Parents also changed their responses over time and became more competent at developing more mindful, more natural, and more directed responses, as well as better boundary management (Sutter \& Ballard, 2009). 
To summarize, transracial adoptive families face a lot of challenges related to the development of the child's racial identity and preservation of a healthy family identity. Research shows that most adoptive parents believe in the importance of cultural socialization for their transracial children and engage in a variety of cultural activities to facilitate a connection with the child's birth culture. Continuing post-adoption counseling, training, and education is highly recommended for racially different families (Zhang, 2010).

\section{Risk and Protective Factors}

The literature shows that families that come together as a result of international adoption face specific challenges, and intercountry adoptees are generally considered an "at risk" population (Viana \& Welsh, 2010). Despite the challenges, however, there are a variety of factors that protect these families from negative effects caused by the child's early experiences. In this section the focus will remain on the risk and protective factors that are unique to families with children adopted from overseas.

According to Hawk and McCall, about $85 \%$ of children adopted from other countries have spent time in institutions (2010). The negative effects of institutionalization are widely documented in the literature as it is not uncommon for institutionalized children to exhibit signs of global developmental delay, including arrest of fine and gross motor skills, cognitive skills, language, and social and emotional development (Welsh et al., 2007). Other common problems are malnutrition, lack of medical care, and neglect (van Londen, Juffer, \& van IJzendoorn, 2007). Many studies have found the length of stay in an institution to be consistently predictive of a negative outcome, especially for those children who live in an orphanage for a year or more (Adoption Institute, 2010; van Londen et al., 2007; Welsh et al., 2007). In addition to that, attachment difficulties, such as disorganized attachment, have been widely documented in 
children who are raised in orphanages (Barth et al., 2005; Juffer, Bakermans-Kranenburg, \& van IJzendoorn, 2005; Shapiro, Shapiro \& Paret, 2010; van Londen et al., 2007). Furthermore, the study of orphanage children in Russia found that newly admitted infants had lower birthweight, poorer Apgar scores, more perinatal complications, and a higher rate of genetic abnormalities than Russian norms (Groark, Muhamedrahimov, Palmov, Nikoforova, \& McCall, 2005, as cited in Welsh et al., 2007). Therefore, international adoptees may have certain biological vulnerabilities that may further be exacerbated by their early depriving environments.

Parents of post-institutionalized adopted children report a higher rate of behavior problems than parents of non-adopted, biological children. Hawk and McCall (2010) reviewed 18 studies that used the Child Behavior Checklist (CBCL) to assess behavior problems in internationally adopted children as compared with non-adopted children, and found that adopted children exhibited more internalizing problems, externalizing problems, attention, and thought problems. Younger children generally scored higher on the Internalizing scale whereas older children scored higher on the Externalizing scale. Hawk and McCall also found that the severity of an early environment was a major factor in children's behavior problems. Thus, thought problems were found to be related to the most severe early environments as found in Romanian institutions of the 1990s. Attention problems, however, were generally elevated across the sample regardless of the severity of early environments (Hawk \& McCall, 2010). Furthermore, post-institutionalized adoptive children received consistently higher CBCL scores than noninstitutionalized adoptive children and biological children (Hawk \& McCall, 2010). It was found that the major factor contributing to extreme behaviors was the child's age at the time of adoption, with older children scoring higher on attention problems and social problems, as well as thought, internalizing, and externalizing problems. The research shows that boys are at a 
higher risk than girls to develop externalizing problems and attention difficulties (Stams, Juffer, \& van IJzendoorn, 2002). Externalizing disorders, particularly aggression and antisocial behaviors, are associated with increased parental stress and dissatisfaction with adoption (Welsh, Viana, Petrill \& Mathias, 2007).

Institutional factors also played a role in the parents' willingness to recommend international adoption as a way to build a family. According to Hellerstedt et al. (2008), $75 \%$ of parents would recommend international adoption with no reservations, $23 \%$ would recommend it with reservations, and $2 \%$ would not recommend international adoption at all. There was a significant correlation between the willingness to recommend international adoption and the amount of time the adoptee spent in an institution, however. Thus, $80 \%$ of parents with children who spent no time or less than 12 months in an institution would recommend international adoption as opposed to only $60 \%$ of parents with children who spent more than 12 months in an institution making such a recommendation (Hellerstedt et al., 2008). Overall, it is evident that intercountry adoptees face a variety of risk factors, including institutional rearing, early abuse and neglect, inadequate health care and nutrition, and inadequate opportunities to form secure attachments (Welsh \& Viana, 2010).

Despite the risk factors, however, it is important to note that "the majority of internationally adopted children do not demonstrate severe and/or persistent medical, behavioral, or developmental problems" (Welsh et al., 2007, p. 286). Studies of institutionalized children reviewed by McGuinnes, Ryan and Robinson (2005) showed that according to their adoptive parents' reports, these children adapt quickly and exhibit competencies in several areas, including academic, social, and personal conduct competence. Furthermore, a 2005 meta- 
analysis of behavior problems by Juffer and van IJzendoorn discovered very small differences between internationally adopted and non-adopted children (Hawk \& McCall, 2010).

Most children are highly resilient and are able to recover even from the most depriving environments (Adoption Institute, 2010). According to various research studies, certain protective factors that play a role in post-adoptive adjustment of children include female gender, easy temperament, ability to develop attachments, adoption early in infancy, and staying in foster care as opposed to an orphanage (Adoption Institute, 2010; van Londen et al., 2007). McGuinnes et al. (2005) studied families with children adopted from the Former Soviet Union and found that with the exception of low birth weight, pre-adoptive risk factors might decline in importance in the presence of certain protective factors. They discovered that cohesive family environments, as defined by the "degree of commitment, help, and support family members provide for one another," were highly beneficial for the adoptees' competence acquisition (McGuinnes, Ryan \& Robinson, 2005, p. 219). Other factors included a higher socioeconomic status that allowed adoptive families to have a better access to services, cognitive stimulation, and other enrichment activities. The parents' high levels of motivation to help their children played an important role as well. McGuinnes et al. (2005) reported that most adoptive children in their sample received a variety of professional interventions, including speech therapy, academic tutoring, and counseling. A study of Israeli parents with internationally adopted children revealed that when compared with parents of domestically adopted children, they tend to have more psychological and familial resources, have more cohesive and supportive family relations, have higher degree of marital adjustment, and engage in more frequent spousal communication (Levy-Shiff, Zoran \& Shulman, 1997). In addition to that, parents with children adopted from other countries were found to utilize a more active, problem-solving approach and 
generally viewed adoption in a highly positive light (Levy-Shiff et al., 1997). Overall, research indicates that despite the vulnerabilities that internationally adopted children possess, they adjust well and overcome early adversity in the presence of a cohesive, loving family environment that is conducive to their growth and development.

So what are the key factors that allow families to build cohesion and facilitate positive adjustment not only for the adoptive children, but for the parents as well? Attachment is one of the most important building blocks of a successful family environment as developing a secure attachment has been called a primary task for parents and children after adoption (Pryor \& Pettinelli, 2011). This task may be very challenging for children who have experienced a lack of warm, sensitive, and responsive caregiver-child interactions early on. In the next section the role of attachment in adoptive family formation will be examined.

\section{The Task of Attachment}

According to Pryor and Pettinelli, "in the adoptive family cycle, the purpose of the adoption process is primarily to accept the new member into the family system" $(2011, \mathrm{p} .47)$. Welcoming an adoptive child into the family is very different than giving birth to a child as the majority of international adoptions occur after infancy, and the critical milestone of developing attachment to a caregiver may have been stalled by the early deprivation. Many authors note that by the time the adoption is finalized, adoptive parents are eager to claim their child, wanting to bond with him or her immediately (Shapiro et al., 2001; Welsh et al., 2007; Wimmer et al., 2010). However, depending on the child's early experiences with caregivers, he or she may actively push the adoptive family away, withdraw from them, or become aggressive toward them (Shapiro et al., 2001). Thus, there may be a mismatch between the adoptive parents' readiness to attach and the child's inability or unwillingness to do so (Shapiro et al., 2001; Wimmer, Vonk, \& 
Reeves, 2010). Research has shown that there is a significant relationship between the child's ability to attach and the adoption outcome, with the adoptee's capacity for attachments being a strong protective factor for adoptive families (Adoption Institute, 2010). For example, one study found that adoption disruption was eight times higher if a mother perceived a lack of attachment by her adopted child (Adoption Institute, 2010). Undoubtedly, developing strong attachment is a major goal for the parents and their newly adopted children to achieve. Without a secure bond, the family may be at risk for dissolution.

Attachment between an adopted child and his or her caregivers is a reciprocal process. According to Tirella, Tickle-Degnen, Miller and Bedell, "how smoothly the child merges into the family unit is often described as the 'goodness of fit' where the expectations and properties of the family unit are in accordance with the child's abilities, character, and behavioral aspects. [...] When the fit is beneficial, the child and the parents are comfortable with each other and have a stable emotional connection, known as mutual attachment" (2012, p. 98). The limited data gathered from domestic adoption and foster care literature show that the mismatch between parental expectations and child characteristics plays an important role in adoption failure (Viana \& Welsh, 2010). Therefore, it is vital for adoptees and their parents to form a bond as early as possible in the adoption process.

There is a vast body of research documenting a high rate of attachment difficulties in an adoptive population (Juffer et al., 2005; Steele, Hodges, Kaniuk, \& Steele, 2010; Versissimo \& Salvaterra, 2006). However, it does not mean that all adopted children have attachment problems. The data on attachment styles vary, but it has been documented that most children adopted in infancy (74\%) are securely attached to their adoptive parents by their first birthday (Juffer et al., 2005; van Londen et al., 2007). This implies that when adopted early, children 
have a normal rate of secure attachment. However, these numbers change greatly if a child is adopted at a later age, or if he or she experienced early deprivation. According to Juffer et al. (2005), the rate of disorganized attachment in adopted Romanian children was at 35\% after eight months of living in an orphanage, as compared to $11 \%$ of disorganization in children who were adopted before the age of four months. These findings suggest that the most optimal adoption outcome occurs if a child was adopted at a very early age, and has experienced a consistent and stimulating caregiving environment prior to and after adoption.

Attachment difficulties are associated not only with the ability to bond with others, but also with more severe psychopathology in adulthood. Attachment disorders have been found to be highly comorbid with externalizing behaviors and aggression (Welsh et al., 2007; Wimmer et al., 2010). Furthermore, both attachment difficulties and behavioral problems are linked to higher parental stress and dissatisfaction with adoption (Welsh et al., 2007). These findings suggest that children who exhibit problems with attachment are more likely to develop other disorders. As a result, parents may feel overwhelmed and dissatisfied with adoption outcome. A recent investigation conducted by Reuters revealed the potential dangers of disrupted international adoptions (Twohey, 2013). An investigative reporter, Megan Twohey, spent 18 months examining eight online bulletin boards designed to help parents find other families for their unwanted children, most of whom were international adoptees. She found that at least $70 \%$ of children advertised on these bulletin boards were foreign-born. According to Twohey, no authority tracks what happens to these children after they are brought to the U.S. Parents who use these online communities to find new homes for their children report numerous difficulties with their adoptees. According to Twohey, "the problems - and the isolation parents feel - can prove overwhelming. On the bulletin boards, parents talk of children becoming abusive and 
violent, terrorizing them and other kids in the household" (2013, http://www.reuters.com/investigates/adoption/\#article/part1). She found that parents who offer their children on these websites report having limited options because of the financial toll of residential treatment centers, lack of belief in social services, and the fear of being investigated for abuse or neglect if they contact the authorities (Twohey, 2013). As a result, they turn to rehoming - a gray zone which potentially opens doors to human trafficking and child abuse as unwanted children are traded between homes with little accountability.

To summarize, one of the main goals of adoptive families is to form a bond between the parents and the children. Unfortunately, adopted children are at an increased risk for attachment problems, and that carries many negative implications. These attachment problems are predictive of a variety of maladaptive responses, which in turn may influence parental satisfaction with adoption. Parents who perceive a lack of attachment on a child's behalf are more likely to be dissatisfied and are at a higher risk for adoption disruption. In order to preserve the family unit and optimize the adoptive experience for parents and children alike, it is essential to study the processes that take place during the post-adoptive adjustment of parents. In the next section the focus will shift to parental adjustment and the common experiences reported by parents of internationally adopted children.

\section{Parental Adjustment}

From the literature reviewed so far it is evident that families formed as a result of international adoption face numerous challenges, including the adoptees' early history, forming attachments, and issues specific to transracial families; however, they possess a variety of protective factors that allow them to overcome most difficulties and to thrive. Most of the research on international adoption historically focused on the adoptees' adjustment, and very 
little attention was paid to the adjustment of parents. Recent events, however, illuminated the plight of some families who are raising internationally adopted children. An incident that occurred in April 2010 sparked an international debate after a Tennessee mother sent her 7-year old adopted son unaccompanied on a plane to Russia with a note that she no longer wished to parent that child (CNN Wire Staff, 2010). More recently, an 18-month Reuters investigation uncovered several online communities "where participants advertised unwanted children, often international adoptees, as part of an informal practice that's called 'private re-homing.' (Twohey, 2013, http://www.reuters.com/investigates/adoption/\#article/about). In order to understand the factors that may lead to adoption disruption in cases like these, it is vital to identify the needs of adoptive families and to study the adjustment of not only adoptive children, but also their parents. In the following section the research on parental experiences, perceptions, and overall adjustment to international adoption will be reviewed.

The framework that is commonly used to understand the lifelong issues faced by all members of the adoptive triad (birth parents, adoptive parents, and adoptees) was developed by Deborah Silverstein and Sharon Kaplan (1982). They suggested that adoption is characterized by the following core issues: loss, rejection, guilt and shame, identity, intimacy, and mastery and control (Silverstein \& Kaplan, 1982). Although every member of the triad is believed to experience them, for the purpose of the study this review will focus primarily on the adoptive parents.

According to Silverstein and Kaplan (1982), the issue of loss permeates the process of adoption for everybody involved. For adoptive parents, it may be the loss of a real child through death or stillbirth, or a dream child through infertility. As a result of this loss, adoptive parents struggle with grief issues. This grief may not be resolved even after the adoption, especially if 
the parents do not view their adopted child as capable of filling the shoes of their dream child. Subsequently, issues of rejection arise when adoptive parents feel rejected by their bodies or by the higher power for not giving them the child they long to have. They may also feel rejected by their adopted child. Internalized feelings of rejection lead to guilt and shame that adoptive families may experience. They may believe that they deserve to be rejected and that there is something intrinsically wrong with them. In addition to that, issues with identity may appear when adoptive families struggle with the loss of generativity and their status of adoptive, as opposed to biological, parents. This may lead to problems with intimacy, as the lack of bonding between adoptive parents and their children may prevent them from establishing a closer relationship. Finally, the issues of control and mastery may arise when adoptive parents are faced with feelings of helplessness and powerlessness. To compensate for that, they may engage in overprotective and overcontrolling behaviors. Overall, these core issues are believed to play a vital role in life adjustment of adoptive parents, birth parents, and their children (Silverstein \& Kaplan, 1982).

Pryor and Pettinelli (2011) conducted a qualitative narrative analysis of international adoption stories and discovered five salient themes for the adoptive parents: loss and choice, emotion-based and logic-based processes, history and heritage, becoming a family, and accentuating the positive and eliminating the negative. According to them, each adoptive family reported some kind of a loss. Whether it was fertility, pregnancy, a child, or a marriage, loss was a factor that precipitated the decision to adopt. International adoption allowed the parents to choose the child's racial and ethnic characteristics, as well as gender and disability status. Adoptive parents also perceived it as a more stable arrangement than domestic adoption because there was no risk of losing the child to biological parents after the adoption was finalized. The 
theme of emotion-based and logic-based processes refers to the parents' intellectual and emotional reasoning during their decision-making processes. The authors found that most parents found paperwork demands quite difficult and "frustrating", and some questions were deemed too personal and unnecessary (Pryor \& Pettinelli, 2011, p. 52). Some parents reported an immediate emotional connection with the child after they found out they were matched with someone while others held back and approached this event with an analytical frame of mind. Similarly, some parents used emotionally charged words and vivid images to describe their first meeting with a child while others focused on logistical details of their arrival to the new country and meeting with adoption officials. Another theme was the child's history and heritage. Many parents reported that there was very limited information on the child's previous history and background. Several families stated that they wanted to incorporate the child's native culture by celebrating holidays and festivals and possibly traveling to the children's birth country when they got older. One family believed that incorporating the child's culture would be difficult and "he might just want to be an all American boy" (Pryor \& Pettinelli, 2011, p. 53). Therefore, this family did not think that cultural education and exposure would be beneficial for their child. The theme of becoming a family was evident during the adjustment period after bringing the new child to the U.S. Some families reported sleep difficulties and illnesses with their children, while for others it was a relatively smooth transition. Parents reported trying different strategies in their attempt to relate to their children and to get to know them better. All families stated that they felt good about developing a bond with their child. Some parents indicated feeling strongly attached to their child within three or four days after adoption while for others it was a more gradual process. Most parents, however, were surprised and excited about developing strong connections with their children. One mother reported that the bond with her adopted daughter 
was as strong as the bond with her biological son. Finally, the last theme uncovered by the authors was the parents' focus on the positive aspects of the adoption experience. Adoptive parents believed that they received a child who was perfect for them and either minimized or downplayed any negative experiences. They were enthusiastic about sharing the child's positive characteristics and reported a sense of wonderment while getting to know their child as a person. Behavioral and developmental concerns were addressed by utilizing outside resources or working within the family.

Another qualitative study that examined experiences of adoptive parents' via thematic interviews was conducted by Hogbacka (2008). She interviewed parents from Finland who adopted children from other countries and organized her inquiry in four phases symbolic of the journey of adoptive parenthood: arriving at the decision to adopt, hopes and anxieties regarding the future child, feelings during the waiting period, and feelings upon the arrival of the child. Hogbacka found that the paths to adoption differed among the participants but were all guided by the participants' powerful desire to have a child (2008). According to Hogbacka, most people in her sample chose to adopt because of issues with infertility, whether they were married or single (2008). Some of them had tried to conceive with the help of reproductive technology and described infertility treatments as "emotionally draining" and "an emotional roller-coaster that one would not wish on anyone" (Hogbacka, 2008, p. 317). The typical story that single women adopters shared was that they did not have a permanent partner while their biological clock was ticking. Thus, "for these women being able to become a mother was clearly more important than having a child with a man at any cost" (Hogbacka, 2008, p. 318). Several families with no fertility problems had a strong interest in transnational adoption, saw it as opening up "new dimensions in life", and simply "felt good about having adopted" (Hogbacka, 2008, p. 318). 
Hogbacka found that parenthood and becoming a family was rooted in identity issues for adoptive parents (2008). To have the child that is "one's own", to be able to act like a family and participate in social activities of families, to have a permanent and exclusive tie with the child, and to have a sole decision-making responsibility for the child were the desired aspects of having the identity of a parent (Hogbacka, 2008, p. 319). When these parents spoke about their hopes and anxieties concerning their child-to-be, one of the main themes was negotiating race, health, age, and gender. Most parents expressed a wish for a young and healthy child. They expressed a desire for their child to have the best possible start in life and for them to be able to play a major role in the child's development. Many parents wanted their adopted child to look like them (“Western looking”), and most preferred to adopt a girl (Hogbacka, 2008, p. 320). Hogbacka noted that the parents' racial and ethnic preferences were related to the fear of being a potential target of racist remarks later in life due to looking different in Finnish society; thus, it was believed that a child would be more protected if he or she looked like the majority in Finland. Although the United States has more racial diversity than Finland, the desire to have a child who is lighter skinned has been reported by different researchers across samples (Hogbacka, 2008).

The waiting period for the parents was reported to be psychologically demanding, with a lot of emotional stress and some expressions of envy. Hogbacka found that it was common for parents to use the internet to monitor not only their own progress but also progress of other adoptive families via discussion groups and online support communities. Families who were less traditional exhibited more anxiety about the possibility of changing policies of sending countries. The uncertainty of the waiting period was reported to be challenging for most parents. Hogbacka described this highly emotional waiting period as "an over-flow of sentimental feeling" evoked by the idea of the child (2008, p. 324). When the participants finally received the child they 
reported an array of emotional reactions, including relief, happiness, joy, pride, and "very strong feelings of attachment" (Hogbacka, 2008, p. 325). An aspect that was somewhat disturbing to the parents was the idea of adoption as a way to obtain the child through exchange. Parents coped with these thoughts by viewing their adoptive experience as fate or necessity. They also found similarities between themselves and their new children and found signs that the child was meant to be theirs (Hogbacka, 2008).

Hogbacka's qualitative study reveals an intricate mix of emotions and cognitions associated with longing for a child and becoming a parent through international adoption. Another qualitative study by Harf, Skandrani, Radjack, Sibeoni, Moro, and Revah-Levy examined first parent-child meetings in international adoptions and the parents' reactions to them (2013). Using Interpretative Phenomenological Analysis, the authors found three principal themes coloring the first meeting with the child: the scene when the child is entrusted to the parents, the discovery of the child's body, and the first parent-child interaction. The parents who were interviewed lived in urban areas of France and adopted children from 20 different countries. According to the authors, when the child was first entrusted to the parents, the three subthemes that the parents reported were the emotional coloring of the scene, the images of the orphanage, and the lack of preparation of the orphanage staff to provide information about the child. The parents described the first meeting as highly emotional - it was either a magical moment or a moment of solitude and anxiety for the parents. Some parents did not share any emotional reaction and instead focused on the description of the context and the scene (Harf et al., 2013). Poor conditions of the orphanages were noted by the parents who were shocked to see the child's environment for the first time. Parents also reported that the staff did not appear 
prepared to answer questions about the child and for the most part, the child was handed to them without providing any previous history about the child.

Many parents described the child's physical condition as poor, often as a consequence of nutritional deficiencies or diseases. As a result, some of them reported feelings of shock, rejection, or withdrawal. The feeling of worry about the child dominated the emotional experience for several parents. The subthemes discovered during the first parent-child interaction were separated into the child's reactions, the parents' emotions in response to the child's reactions, and the meaning that the parents attributed to the child's reactions. Among the child's reactions were accepting contact or reactions of aggression and rejection, including agitation, anger, and acting out. Based on the child's reaction, the parents described their experience either as intense happiness or worry, not knowing what to do, and not having expected this. In order to make sense of this experience, parents tried to explain the child's reactions and understand them. Consistent with other qualitative inquiries, Harf et al.'s findings illustrate the emotional toll experienced by the parents in the process of international adoption.

Tirella, Tickle-Degnen, Miller and Bedell (2012) further studied the challenges faced by nine parents of newly adopted international children and the strategies they employed to cope with them. They found that the biggest challenges these parents experienced after bringing their children home were with sleeping, feeding, attachment, and the child's behavior. According to the authors, the parents reported that their stress revolved primarily around feeling exhausted, worrying about poor feeding, adjusting to the arrival of the child, juggling work and childcare, and child proofing (Tirella, Tickle-Degnen, Miller \& Bedell, 2012). In order to cope with these challenges, the parents utilized outside resources, such as talking to family and friends and engaging early intervention specialists. They also participated in well-being activities, like 
yoga, and attended educational adoption workshops. Adoptive parents reported that having two parents at home alleviated the stress while a single parent confirmed the struggle of parenting alone. Among the protective factors reported by these families were maintaining a strong marital relationship, getting support from the extended family, and having positive parental perceptions (Tirella et al., 2012).

Another framework that emerges from the review of pertinent literature on parental adjustment is offered by Shapiro, Shapiro and Paret (2001) in their paper on the formation of new family attachments after an international adoption. According to the authors, the unifying motif for adoptive parents who are looking to adopt from overseas is an unfulfilled longing for a child. Parents who choose to adopt a child from another country may likely have exhausted other options to conceive. They may or may not have gone through fertility treatments, experienced a loss, or other life-changing events. Other parents may be driven by altruistic feelings when they decide to adopt internationally (Shapiro, Shapiro \& Paret, 2001). They may find comfort in knowing that they are providing a better future for a child in need. Whatever the reasons are, the process of international adoption requires patience, commitment, and many sacrifices on behalf of adoptive families. Other studies reviewed here also emphasize an overwhelming desire to have a child and parental feelings of loss.

Similar to the findings of other authors, Shapiro et al. (2001) described the shock that many adoptive parents experience at the first sight of the child's environment. Despite the initial reaction, parents often report immediately falling in love with the child and wanting the child's acceptance and affection in return. This may not be reciprocal on the child's behalf, who may view the adoptive parents as strangers. Sometimes the child pushes them away or becomes aggressive toward them. Other literature also supports the existence of a disparity between the 
adults' and the child's readiness to attach (Harf et al., 2013; Welsh et al., 2007; Wimmer et al., 2010). Many times, it is a sobering experience for the parents who begin to realize that their love and affection alone may not be able to overcome the difficulties of parenthood that lie ahead. Parents may grieve for themselves and the child, and they may start doubting their competence and their evolving sense of parental identity. Adjusting to parenthood can initially be very challenging for adoptive families and may affect the parents' self-esteem and self-confidence.

Further, Shapiro et al (2001) described the struggles adoptive parents may experience when they bring their children home. There may be feelings of rejection, loss, and inadequacy, especially if the child manifests attachment difficulties (Barth et al., 2005). In the beginning, parents may believe that their unconditional love and support will solve these problems. When it becomes clear that it may not be enough, parents often begin to seek services of different specialists. A high need for support that adoptive parents exhibit is noted by many researchers (Adoption Institute, 2010; Barth et al., 2005; Welsh et al., 2007). Despite this high need, special services for adoptive families are scarce, as there are few mental health professionals who specialize in post-adoptive issues (Adoption Institute, 2010). As a result, parents may feel frustrated, resentful, and isolated. It appears that the availability of specialized support for adoptive families is likely to affect satisfaction with adoption and overall adjustment of adoptive parents.

Other factors that affect parental adjustment are developmental and behavioral problems that adopted children may exhibit. Such problems, along with attachment difficulties, are correlated with parental stress and dissatisfaction with adoption (Welsh et al., 2007). The parents may feel consumed by the plethora of their child's special needs and overwhelmed by caring for him or her. This may be further exacerbated by a lack of parental preparation and 
unawareness of the risks and implications of international adoption. Sometimes pre-adoptive information does not accurately reflect the adoptee's early history or special needs that he or she may have. This is an important factor in post-adoptive family adjustment as the research indicates that a lack of accurate pre-adoptive information is associated with parental dissatisfaction and adoption failure (Welsh et al., 2007).

Still, these challenges generally do not overshadow the special fulfillment that a child brings to many adoptive parents (Shapiro et al., 2001). They may find satisfaction in witnessing gradual progress in their child's adjustment and knowing that that they are providing the child with a better future. Adoptive parents may also experience special joy in slowly building trust with their child and winning his or her affection. Overall, as it has been mentioned previously, adoptive experience is highly rewarding and fulfilling to many families. Adoption outcome studies show that despite all the challenges, over $90 \%$ of adoptive families are highly satisfied with their adoptive experience and would go through that process again having full awareness of what it is like (Adoption Institute, 2010).

Successful post-adoptive adjustment depends on many factors that contribute to the overall well-being of the family. The review of the literature identified several strengths that serve as protective factors for adoptive families. First of all, it is the importance of a stable marriage or partnership. Second, it is an open communication within the family. Rueter and Koerner (2008) have linked effective communication with fewer externalizing problems in adolescents (as cited in Adoption Institute, 2010). The third factor is the nurturing and positive family interaction combined with authoritative parenting style. For example, a longitudinal study of adoptees from Russia found that a cohesive family environment was predictive of fewer behavioral problems and a higher sense of competence in adoptees (Adoption Institute, 2010). 
Another protective factor is the capacity to cope with stress and challenges, or the degree of resiliency that the families exhibit. In addition to that, realistic expectations and careful parental preparation play a role in successful adjustment as well. This includes accurate pre-adoptive information on a child, full awareness of his or her needs, and readiness to address problematic behaviors. Finally, another critical factor in positive parental adjustment is the availability of outside support for the family. As it has been stated before, adoptive families express a high need for support and are two to five times more likely to seek professional help than biological families (Adoption Institute, 2010; Barth et al., 2005; Welsh et al., 2007). Adoption affects not only the immediate family, but many other systems, including schools, communities, and a variety of professional services. Naturally, a supportive environment leads to a better outcome for not only adopted children, but their parents as well.

Overall, adoption is a highly positive experience for a vast majority of families. On the other hand, it can also be a very challenging experience. The reviewed literature suggests that adoption evokes a variety of responses from parents, including excitement, shock, unconditional love, extreme stress, feelings of inadequacy, isolation, and satisfaction, to name a few. The adoption journey is more likely to be successful if such protective factors as stable partnership, open communication style, positive parenting style, resilience, realistic expectations, and outside support systems are present. However, the existing framework for understanding the processes that adoptive families experience is insufficient and lacks empirical data. There is a high need for more research on parental adjustment and its relation to adoption satisfaction. Therefore, this study will attempt to identify the needs that parents exhibit after adopting a child from overseas and provide an understanding of their adoption journey through a qualitative design. The research questions that will be addressed in this inquiry will be the following: 
1. How is the process of international adoption experienced by the adoptive parents?

2. Are there common themes associated with psychological adjustment for parents who adopted children from overseas, and if there are, what are these themes?

3. What are the needs of families with children adopted from overseas? 


\section{CHAPTER 2}

\section{Methods}

\section{Research Design}

Qualitative research was chosen as the most appropriate method for studying this topic because there is much to learn about the experiences and needs of parents who adopted children from overseas. Qualitative methodology is usually used when the issue needs to be explored and understood on a more complex, detailed level; when the context needs to be considered; when the mechanisms or linkages need to be explained; or when theories need to be developed (Creswell, 2013). Among many approaches to conducting qualitative inquiry, thematic analysis of family narratives was selected as the most suitable design for this study. One of the advantages of thematic analysis is that it can be used within different theoretical frameworks (Braun \& Clarke, 2006). Specifically, thematic analysis was used as a tool within a narrative analysis tradition to identify, analyze, and report themes in the participants' narratives. The main premise of narrative research is that people make meaning of their lives through the stories they tell (Josselson, 2011). Narrative researchers examine the issue as a whole rather than studying its separate parts. As such, Schleiermacher's idea of the "hermeneutic circle" is fundamental in understanding the meaning making process in narrative inquiry (Josselson, 2011). The stipulation of Schleiermacher's idea is that "it is not the parts that are significant in human life, but how the parts are integrated to create a whole," meaning that "an understanding of the whole illuminates the parts, which in turn create the whole" (Josselson, 2011, p. 226). Thus, the tradition of narrative research served as an inspiration during the principal investigator's thematic analysis as it allowed her to highlight the emotional journeys of the families and to examine their meaning making processes. 
This researcher believes that thematic analysis as a tool of qualitative inquiry offered a valuable insight into the stories of international adoption through the parents' perspectives and identification of their unique needs. This knowledge is greatly beneficial for mental health professionals who work with such families as it can inform their therapeutic approach and the types of interventions that would be most effective. Although American parents adopt more children from overseas than parents from any other country, there is a lack of comprehensive qualitative research on parental experiences with international adoption. The existing qualitative inquiry regarding this topic described more specific aspects of international adoption, such as transracial issues, first parent-child interactions, post-adoptive adjustment, or focused on experiences of parents from other countries, such as Finland, Australia, and Israel. One of the notable studies that attempted to understand how American families construct their narratives of international adoption experiences was conducted by Pryor and Pettinelli (2011). The authors used a narrative analysis approach to identify salient themes that prevail in the adoptive families' experiences (please see the section on Parental Adjustment for the overview of the authors' findings). Pryor and Pettinelli (2011) analyzed the archival data from the "earlier longitudinal research study conducted by the International Adoption Clinic (IAC) at Saint Louis University to understand the effectiveness of the IAC protocol used to assess internationally adopted children and their families" (Pryor \& Pettinelli, 2011, p. 47). Although their findings are greatly informative, there are several important limitations that warrant further research. First, the authors used the archival data that was collected and transcribed by clinicians several years prior to the narrative analysis, between 2005 and 2006. As a result, the participants could not review their interviews for member checking, which prevented further in-depth investigation and clarification. Second, during the data collection phase there were several different interviewers 
who met with the families to collect the data. This may have added extra variability to the study and potentially affected the results. Third, the interviews were conducted with the entire family present, and the authors noted that the time allotted for the interview was frequently interrupted by tending to young children. Fourth, the selection criteria for the participants included only families that adopted children from overseas within the previous six months and excluded families who adopted children with disabilities. In their discussion section the authors noted that during that period the parents were still getting to know their children and did not report any desire to address problems or challenges. In fact, the stories that the participants told during that post-adoption period were "very happy" (Pryor \& Pettinelli, 2011, p. 57).

Including the families who lived with their adopted children for a longer period of time and not limiting the selection criteria to families who adopted only healthy children without disabilities provides a fuller range of described experiences and a better understanding of the families' needs. Thus, the present study addressed the limitations of Pryor's and Pettinelli's research as well as added another layer of inquiry into the needs of the families. Unlike Pryor's and Pettinelli's study that examined the families' construction of an autobiographical narrative six months after international adoption, this research was aimed toward understanding the experiences of adoptive parents at different points of time.

In order to obtain the stories, the researcher used semi-structured interviews with parents who adopted children from other countries in the past ten years. The sample was collected using a snowball sampling technique, in which the participants volunteered to contact other adoptive families they knew. The principal investigator administered a brief demographic questionnaire prior to conducting in-person interviews with the parents. Families who agreed to participate in 
the interview received a 50-dollar gift card to Target or Wal-Mart stores. The following sections describe the study in more detail.

\section{Participants}

According to Creswell, there are no specific guidelines pertaining to the number of participants necessary to conduct a qualitative inquiry because the greater number of participants does necessarily provide a deeper understanding of their experiences (2013). One must consider the researcher's available resources needed to conduct this study in the most accurate, ethical, and appropriate manner (Marshall \& Rossman, 2006). When conducting narrative inquiry, researchers are never mere recorders of someone else's life story because in their inquiry they become a part of that experience (Clandinin \& Connelly, 2000). Due to the fact that this research was conducted single-handedly by one principal investigator, it is important to consider the demands that qualitative analysis presents to the researcher and the time commitment for the analysis of each story. Therefore, having seven participants is what this researcher considered appropriate and manageable. Recruiting more than seven participants may have compromised the quality of the data as there would have been less time devoted to the analysis of each story, and the analysis may have become mentally exhausting for the researcher. Interviewing less than seven participants may not have provided enough variability in the families' accounts of their experiences. "The intent in qualitative research is not to generalize the information [...], but to elucidate the particular, the specific" (Creswell, 2013, p. 157). Therefore, recruiting seven families was the most reasonable number of participants, given the qualitative nature of this study and the investigator's own resources.

The participants for this study were selected via purposeful sampling, which is a common sampling technique used in qualitative research (Creswell, 2013). As part of this strategy, the 
researcher chooses the individuals who can purposefully inform an understanding of the phenomenon and provide rich qualitative data for the analysis (Creswell, 2013). As with any qualitative research, it is important to consider who to sample and how many participants to interview for this particular study. Therefore, the following selection criteria were imposed: (1) participants must be U.S.-born parents who have adopted one or more children from another country during the past ten years; (2) they must be currently living with that child (or children); and (3) the age of the child(ren) at the time of adoption must range between 1 month and 12 years old (if having adopted a sibling group, the oldest child must be no older than 12 years old at the time of adoption). In order to participate in the study, participants could be legally married, partnered but not legally married, or single. Participation in the study was not open to same-sex families due to the possibility of adding extraneous variables that may have shifted the focus of this research. The researcher was interested to learn about experiences of American parents as opposed to experiences of parents from other countries; therefore, the selection criteria were limited to the U.S.-born parents. In order to provide a greater variability in the families' stories and to examine a wider chronological account of their experiences, it was important to include parents who adopted children within the past ten years as opposed to the six month cutoff mark reported by Pryor and Pettinelli (2011).

In order to qualify for the study, the adopted children were to be no more than 12 years of age at the time of adoption. Statistical data show that a wide majority of children are adopted before that age. In addition to that, there was a speculation that older age at adoption may present different challenges for the parents, which may be beyond the scope of this thematic analysis. Additionally, adoption of sibling groups was admissible for the purpose of this study as long as the oldest child was no more than 12 years old at the time of adoption. Due to the 
study's focus on international adoptions, adopted children could come from any country other than the United States. Parents who have their own biological children were allowed to participate as long as they had met other selection criteria.

The interviews were conducted with the self-identified primary caregiving parent regardless of his or her gender. If desired, both parents could be present during the interview. The interviews took place either in person or over the phone, whichever was preferred by the participants. A potential downside of a phone interview was the researcher's inability to see the participants and gage their responses, which may have affected her rapport with them. In order to compensate for that and to make the participants feel more at ease, the investigator engaged in small talk in the beginning of the interview. She also checked in on the interviewees frequently during the course of the conversation.

Although such variables as parental age, marital status, socio-economic status, education, occupation, ethnic heritage, and having biological children did not play a role in participant selection, this information was collected as part of the demographic data. The demographic questionnaire is attached in the Appendix. The participants were recruited from the greater Morgantown, West Virginia area; greater Pittsburgh, Pennsylvania, area; and from the greater Baltimore, Maryland, and Washington, D.C., areas. These locations were chosen for two primary reasons. First, they offered a diverse sample of communities and yielded a greater range of experiences by the participants. Second, the principal investigator had to consider the driving distance in order to be able to interview the participants face to face. Thus, the sample was recruited near these locations. 


\section{Procedures}

After receiving the Institutional Review Board approval from West Virginia University, the researcher utilized the snowball sampling technique to recruit the participants. This technique "identifies cases of interest from people who know people who know what cases are information-rich" (Creswell, 2013, p. 158). In other words, the researcher solicited information about families who adopted children from overseas from her professional and personal contacts. Two families were identified in the process. The investigator provided them with the study description as well as her contact information, and informed them about a 50-dollar incentive for participation. Both families offered to introduce the study to other adoptive families they knew and provided the researcher's email address and phone number to other participants.

After the potential participants initiated contact via email, they were informed about the nature of the study and the benefits from participation. Those who agreed to participate received the informed consent form and a brief demographic questionnaire via email. The informed consent outlined the confidential nature of this research study and the participant's right to discontinue the study at any time. The participants were encouraged to call or email the principal investigator if they had any questions about the study. The demographic questionnaire included questions about the participants' age, race, marital status, education, occupation, whether or not they have biological children, and income level. Other questions in the questionnaire included information about the adopted child; specifically, age, race, age at the

time of adoption, the year when the adoption was finalized, and the country from which the child was adopted. Please see the Appendix for the questionnaire. The length of time required to complete the demographic questionnaire was predicted to take no more than 10 minutes. 
Participants returned the demographic questionnaire either via email or in person when they met for the interview.

Two families chose to have face-to-face interviews and five families were interviewed over the phone. The face-to-face interviews took place in the participants' homes. The locale was chosen because of its privacy and convenience for the families. In both instances, the children were present in the house but were not part of the interview. The children did not present any major distractions for the parents as they were primarily out of sight during the meeting. The interviews lasted between 40 minutes and one and a half hours. Predictably, it took less time to interview parents who adopted one child and more time to interview families who adopted two or more children. All interviews were audio recorded using a digital recorder with the participants' verbal permission. Confidentiality of the data was emphasized.

Participants were reminded that they were free to discontinue their participation at any time and were presented with opportunities to ask questions about the study. Having a good rapport with the families was essential for successful data collection in this research study; therefore, the first few minutes of the interview were spent getting to know the participants and building rapport with them. The researcher disclosed information about her professional interests if participants inquired about them.

All interviews were conducted by one principal investigator. According to Kvale and Brinkmann (2009), research interviewing is a skilled craft, and special training is desired for those researchers who work with qualitative data. The principal investigator's Master's degree in counseling psychology and several years of experience of conducting clinical interviews with clients make her a highly qualified individual to collect data using qualitative interviews. The researcher utilized her professional expertise in interviewing people in order to obtain narratives 
of their experiences. More specifically, she used reflective listening, silence, open-ended questions, clarifying statements, redirection back to the topic, and unconditional positive regard during interviewing. She started the interviewing process with getting to know the participants and engaging in small talk in order to build rapport. The interviews had a semi-structured format in which the participants were asked open-ended questions about their experiences regarding the adoption and their families' needs. The semi-structured format was chosen as the most appropriate for the purpose of this study because it preserves consistency across the sample while providing an opportunity for the participants to elaborate on their unique experiences (Kvale \& Brinkmann, 2009). The interview protocol consisted of eight questions. The interviews had an exploratory nature, and the participants were encouraged to elaborate on their statements by variations of verbal prompts, such as "Please tell me more about it." After completing the interviews, the participants were debriefed and encouraged to email the researcher if they had further questions about the study.

The data was analyzed according to the stipulations of qualitative research. The thematic analysis of the interviews was guided by narrative tradition. In narrative inquiry, "analysis is aimed at discovering both the themes that unify the story and the disparate voices that carry, comment on, and disrupt the main themes" (Josselson, 2011, p.226). A narrative researcher attempts to gain an overall sense of meaning of the data and then examine its parts in relation to it (Josselson, 2011). According to Josselson (2011), this involves "changing our understanding of the whole until we arrive at a holistic understanding that best encompasses the meanings of the parts" (p. 228).

Although there is no specific procedure pertinent to qualitative data analysis, most qualitative studies contain the following core elements: coding the data, merging the codes into 
broader categories or themes, and comparing and displaying the data using graphs, tables, and charts (Creswell, 2013). For this study, Marshall and Rossman's (2006) procedural steps for qualitative data analysis were utilized. This framework was also used by Pryor and Pettinelli (2011) in their narrative inquiry of international adoption stories.

The first step in this thematic analysis focused on organizing the data. This included transcribing the interviews into text verbatim and storing the records on a secure, passwordprotected drive that was accessible only to the primary investigator. Interview transcriptions were done by the primary researcher herself and facilitated her immersion into the data. The text was read and re-read multiple times in order to develop a detailed knowledge of the story. Next, the researcher reduced the data by generating categories from the narratives. The purpose of creating these categories was to discover patterns and themes that best described the participants' stories. The researcher looked for patterns in the narratives and examined the data for similarities and dissimilarities. Abstracts of similar information were grouped together to form concepts. During this time the investigator included specific quotes from the narratives that illustrated the emerging concepts. According to Marshall and Rossman (2006), it is necessary to code the data more than once as new categories emerge and others collapse. Throughout the data analysis process, the researcher also took memos in form of short phrases, ideas, or key concepts that developed during reading of the transcripts.

The purpose of this analysis was to uncover themes in the data. Therefore, the final step in this process was to offer integrative interpretation. During this phase it was important to search for other reasonable explanations for the emerging story and challenge patterns that may appear obvious (Marshall \& Rossman, 2006). Special consideration was given to preserving confidentiality of the participants and anonymity of the data for publication. All names were 
changed; however, certain information, such as the country of the child's birth, the child's age at adoption, and the child's race remained unchanged. In an attempt to make the participants less identifiable, the current geographic location of the families is described in broad terms, for instance, the Greater Pittsburgh area or the Greater Baltimore area.

\section{Measures}

Demographic Questionnaire. Information regarding the participants and their adopted children was collected using a brief demographic questionnaire that was emailed to the participants before the interview. The length of time required to answer demographic questions was estimated to be no more than 10 minutes. The participants were asked to provide information about their age, race, marital status, education, occupation, and income level. Other questions included the child's age at the time of adoption, the child's country of origin, and the year when the adoption was finalized. Please see the Appendix for the questionnaire.

Interview. The interview had a semi-structured format in which the participants were asked open-ended questions about their experiences during the adoption journey. The interview protocol consisted of eight questions in the following order:

1. How did you come to a decision to adopt a child from another country?

2. What was the adoptive process like for you?

3. Please describe the first few months with the newly adopted child.

4. How did the child fit with your nuclear family and the extended family?

5. Have you experienced any issues in regard to your child's ethnic background? If so, please describe them.

6. What were the supports and other resources available to you in your adoption journey? 
7. How can the services in the professional community meet your needs better?

8. What would be one sentence/word summary that describes your entire adoption journey?

In addition to answering the questions, disclosing any other related adoptive experiences was encouraged through such prompts as "Please tell me more about it." In order to build smooth transitions and normalize the participants' experiences, the researcher occasionally started her questions with general statements, such as, "It is not uncommon for adoptive families to seek professional services and to turn to resources in the community. What were the supports and other resources available to you in your adoption journey?" The researcher clarified questions that the participants had during the interview. Throughout the interview, the investigator was careful to maintain a researcher role and avoided engaging in a therapeutic relationship with the participants. For example, in an instance when the mother started crying, the researcher maintained a neutral stance and encouraged her to take as much time as she needs to compose herself. The researcher refrained from processing the emotion with the participant in order to avoid blurring the boundaries.

The investigator followed Irving Seidman's (2006) guidelines on interviewing technique, which include listening rather than talking, asking additional questions to clarify the statements, avoiding leading questions, following up without interruption, limiting self-disclosure, tolerating silence, and following hunches. Additionally, the researcher relied on her own interviewing skills and professional experience, which developed from conducting several hundred intake interviews throughout the course of her master's and doctoral training. 
At the end of the interview the parents were thanked for their participation and were given the researcher's contact information. They were also presented with a choice of a 50dollar gift card to either Target or Wal-Mart that was emailed to them after the interview.

\section{The Role and Background of the Researcher}

One of the main threats to validity of any qualitative research may be researcher bias (Clandinin \& Connelly, 2000; Creswell, 2013; Kvale \& Brinkmann, 2009). All researchers have their own views, attitudes, and ideas about inquiry, and these personal narratives may influence interpretation of stories that participants provide. As Clandinin and Connelly pointed out, "we are forever struggling with personal tensions as we pursue narrative inquiry" $(2000$, p. 46). Therefore, it is important for researchers to "reconstruct their own narrative of inquiry histories and to be alert to possible tensions between those narrative histories and the narrative research they undertake" (Clandinin \& Connelly, 2000, p. 46). As the principal investigator of this study, I too hold certain inherent biases that have been formed as a result of my own life experiences, both personal and professional. In this section I will summarize my personal experiences, cultural background, and professional training that played a role in developing a professional interest in this dissertation topic. I will also discuss the impact that the families' narratives had on me as a researcher and an individual.

"Narrative inquiries are always strongly autobiographical. Our research interests come out of our own narratives of experience and shape our narrative inquiry plotlines" (Clandinin \& Connelly, 2000, p. 121). I am a doctoral candidate in counseling psychology and the trajectory of my professional career has exposed me to very distinct populations through the years. I have worked with children diagnosed with Autism Spectrum Disorders and their families; adults with psychiatric disorders, adults with substance use disorders, and finally, college students. In my 
professional career I have worked with a limited amount of foster families and never with families of internationally adopted children. My work with foster families exposed me to different types of family environments; however, my lack of experience with clients who adopted children from overseas means that I have limited professional knowledge of what those family environments are like. Nevertheless, I believe that I have sufficient knowledge to be sensitive and understanding of some differences that adoptive families exhibit, and yet be openminded enough to let new information in and develop a better understanding of their experiences.

I must add that am also a mother and parenting issues naturally present a great interest to me. It is important to mention that I am raising a biological child, however. On one hand, I am well aware of some universal challenges that parents experience when raising children; on the other hand, becoming a parent through adoption is a unique experience with which I am not familiar. Being a parent may lead to false assumptions about what parenting is like for everybody; however, I am fully aware that adoptive families have distinct challenges, and their life journeys are not always comparable with the journeys of biological families. In fact, hearing stories of my participants was a truly inspiring and humbling experience for me. The commitment, dedication, and hard work that these individuals put into becoming parents made me realize that perhaps, I took my own motherhood for granted. I found myself admiring the grace with which these families overcame hardships and their overall resilience. I am very grateful to my participants for allowing me to have a glimpse into their lives; this was truly an eye-opening experience for me. I came to see my uneventful pregnancy followed by the birth of a healthy child as a privilege and I developed a heartfelt appreciation for the journeys of adoptive parents who may not have that privilege. 
During the interviews several families became curious about the nature of my interest in the topic of adoption. I was transparent with them about my background and I welcomed any questions that they had. I explained to my participants that the nature of my interest lies in deep empathy that I have for children without parents and for adults who yearn to have a child but are unable to have one, or adults who choose to adopt out of altruistic purposes. Furthermore, my core belief is that children should be raised by a consistent set of caregivers who will offer them lifelong nurturing and support as secure attachment is extremely important in lifelong adjustment of humans. Therefore, it is essential to provide a child with consistency of care and nurturance as early in life as possible. In cases of children without parents, there is often a lack of that consistency, which is why I wholeheartedly support adoption. I believe that my genuine and unconditional positive regard toward adoption is an asset to this study. It helped me establish rapport during the interviews and as a result, yielded rich stories. However, this bias may have potentially hindered my objectivity. This is why examining my own beliefs about adoption and seeking consultation with my colleagues and supervisors was important during this process.

Additionally, being born and raised in Russia played a great role in forming my worldview and influenced my interest in multiculturalism. When I was a teenager, I visited a Russian orphanage as part of a charity mission in my high school, and I saw firsthand the need for love and nurturing that these children manifest. The children that I saw lived in adequate conditions; however, they viewed every visiting adult as their potential parent, sometimes asking them, "Are you my mother?" This early emotional experience has colored my conviction that every child should have a parent.

I believe that my multicultural background posed an advantage in conducting this research. All families who adopt children from other countries become bicultural as a result of 
international adoption. During their adoption journeys these families have experienced unique struggles and joys that are not well understood by people around them. Talking to a person who not only has a professional background in counseling psychology but comes from a bicultural background herself potentially facilitates better rapport and connection during the interview. In addition to that, I was open to sharing my story about visiting a Russian orphanage with my interviewees if they asked about the nature of my interest in international adoption. It is important to keep in mind, however, that my one-time experience at the orphanage does not account for other environments and conditions that internationally adopted children come from; therefore, I tried to avoid making any assumptions or generalizations about others' experiences. I believe that my professional training in counseling psychology offers me a great advantage in conducting qualitative inquiry as well. As a doctoral candidate in counseling psychology I have extensive experience in interviewing people and organizing their life stories into cohesive case conceptualizations. Witnessing other people's narratives is a routine task for a mental health professional, and this may have presented both advantages and challenges to this study. Among the advantages are the professional interviewing skills that I possess: listening, establishing rapport, conveying empathy, tolerating silence, asking open-ended questions, and following my hunches. The biggest challenge, however, is maintaining the boundary between conducting research and engaging in therapy. It is important to avoid a therapeutic relationship when conducting qualitative research because therapists' and researchers' goals are completely different (Kvale \& Brinkmann, 2009; Seidman, 2006). As a researcher, my goal is to learn from these families, and not to treat them. In order to maintain a researcher role, I planned to routinely consult with my colleagues and supervisors and do additional readings on this topic. 
To summarize, qualitative inquiry implies use of self as an instrument. To be the best instrument that I can, I constantly try to expand my self-awareness, continue to educate myself on proper techniques, and consult with colleagues and supervisors when problems arise. This study has been an eye-opening experience for me and I am humbled to have had an opportunity to witness these families' narratives. It was especially rewarding to hear several families thank me for my interest in this topic and for giving them the space to share their stories. I hope that the knowledge gained from this research will benefit adoptive families through educating the professional community about their experiences and current needs. 


\section{CHAPTER 3}

\section{Results}

The purpose of this study was to examine the participants' narratives in an attempt to understand their experiences with international adoption. The stories were recorded and then transcribed verbatim by the primary researcher. The author then went through each transcript and highlighted the most pertinent content (Marshall \& Rossman, 2006). The findings were further reduced into smaller chunks of data which highlighted the commonalities and differences in participants' experiences. The researcher paid particular attention to the frequency with which certain themes came up in the narratives and then searched for themes that illustrated different points of view. In addition to that, the researcher was also interested in experiences that were unique. This approach resulted in the data that is rich and broadly covered; the data that ensures that everybody's voices are heard; the data that provides a deeper understanding of the participants' narratives.

This chapter is organized in the following way: first, it provides a table and a descriptive overview of demographic data on the participants; second, it illustrates the findings in a brief table summary; and third, it expands these findings through a detailed thematic analysis of the narratives supported by direct quotes from the participants. Table 1 contains information on the family composition, based on the demographic data collected from the mothers. Please note that the mothers' names have been changed. 
Table 1. Family composition.

\begin{tabular}{|c|c|c|c|c|c|c|c|}
\hline $\begin{array}{c}\text { Mother } \\
\text { Age/Marital } \\
\text { Status/Race }\end{array}$ & $\begin{array}{l}\text { Adopted } \\
\text { more } \\
\text { than } \\
\text { once? }\end{array}$ & $\begin{array}{c}\text { Birth } \\
\text { countries }\end{array}$ & $\begin{array}{l}\text { Child } \\
\text { Race }\end{array}$ & $\begin{array}{c}\text { Child } \\
\text { Age at } \\
\text { adoption }\end{array}$ & $\begin{array}{l}\text { Child } \\
\text { Age } \\
\text { now } \\
\text { (years) }\end{array}$ & $\begin{array}{c}\text { Bio } \\
\text { children }\end{array}$ & $\begin{array}{c}\text { Children } \\
\text { total }\end{array}$ \\
\hline $\begin{array}{l}\text { Karen, } 35 \\
\text { Separated } \\
\text { White }\end{array}$ & No & Russia & White & $13.5 \mathrm{mo}$ & 5 & 0 & 1 \\
\hline $\begin{array}{l}\text { Alice, } 45 \\
\text { Married } \\
\text { White } \\
\end{array}$ & Yes & $\begin{array}{l}\text { Russia } \\
\text { Russia }\end{array}$ & $\begin{array}{l}\text { White } \\
\text { White }\end{array}$ & $\begin{array}{l}15 \mathrm{mo} \\
18 \mathrm{mo}\end{array}$ & $\begin{array}{c}10 \\
5\end{array}$ & 0 & 2 \\
\hline $\begin{array}{l}\text { Sandy, } 44 \\
\text { Married } \\
\text { White } \\
\end{array}$ & No & Guatemala & Hispanic & $11 \mathrm{mo}$ & 7 & 0 & 1 \\
\hline $\begin{array}{l}\text { Judy, } 42 \\
\text { Married } \\
\text { White }\end{array}$ & No & Kazakhstan & White & $8 \mathrm{mo}$ & 9 & 1 & 2 \\
\hline $\begin{array}{l}\text { Lilian, } 37 \\
\text { Married } \\
\text { White } \\
\end{array}$ & Yes & $\begin{array}{l}\text { Kazakhstan } \\
\text { Kazakhstan } \\
\text { S. Korea }\end{array}$ & $\begin{array}{l}\text { White } \\
\text { White/Asian } \\
\text { Asian }\end{array}$ & $\begin{array}{l}8 \text { years } \\
4 \text { years } \\
24 \text { mo }\end{array}$ & $\begin{array}{c}14 \\
10 \\
3 \\
\end{array}$ & 0 & 3 \\
\hline $\begin{array}{l}\text { Melinda, } 45 \\
\text { Married } \\
\text { Hispanic }\end{array}$ & Yes & $\begin{array}{l}\text { Colombia } \\
\text { S. Korea } \\
\text { S. Korea } \\
\end{array}$ & $\begin{array}{l}\text { Hispanic } \\
\text { Asian } \\
\text { Asian } \\
\end{array}$ & $\begin{array}{l}1.5 \mathrm{mo} \\
9 \mathrm{mo} \\
11 \mathrm{mo} \\
\end{array}$ & $\begin{array}{c}13 \\
8 \\
7 \\
\end{array}$ & 1 & 4 \\
\hline $\begin{array}{l}\text { Casey, } 38 \\
\text { Married } \\
\text { White }\end{array}$ & No & $\begin{array}{l}\text { Kenya } \\
\text { Kenya }\end{array}$ & $\begin{array}{l}\text { Black } \\
\text { Black }\end{array}$ & $\begin{array}{l}5.5 \text { years } \\
24 \text { mo }\end{array}$ & $\begin{array}{c}12 \\
9\end{array}$ & 2 & 4 \\
\hline
\end{tabular}

\section{Demographic Information}

Of the seven interviews completed for this study, two were conducted face to face (Lilian and Casey), and five were conducted over the phone. Mothers were present in all seven instances, and fathers participated in two of the interviews (with Alice and Lilian). In these two instances the mothers were the primary narrators and the fathers contributed intermittently. The demographic information reported in this study was collected from the mothers; therefore, it provides information on mothers only. The mothers' ages ranged from 31 to 37 years old at the time of their first adoption, with the mean age of 33 years old. At the time of the interview the mother's ages ranged between 35 and 45 years old, with the mean of 41 years old. One adoptive 
mother identified as Hispanic (Melinda); all others identified as Caucasian. All mothers were married at the time of adoption; six of them were married to the same partner at the time of the interview, and one listed her status as separated from her husband with whom she adopted a child (Karen). The combined household income was reported to be $\$ 100,000$ or more by six families. One family, which identified as a single parent household, reported a current income of less than $\$ 100,000$ (Karen). Three mothers reported having a Bachelor's degree (Karen, Lilian, and Melinda), and four reported having a Master's degree. Three families indicated that there were biological children living in their household in addition to the children they had adopted (Judy, Melinda, and Casey). The demographic data collected for this study was consistent with the existing literature that describes families who adopt children internationally as being older, more educated, and having more economic resources than an average American family with biological children (Hellerstedt et al., 2008).

The adoptions described in this study were finalized between 2002 and 2014 with a total of 13 children adopted by the participants. The countries from which the families adopted their children were Russia (3), Kazakhstan (3), Guatemala (1), Kenya (2), Colombia (1), and South Korea (3). The total number of adoptions was 11. Two families adopted two children in one adoption (Lilian adopted a sibling group from Kazakhstan, and Casey adopted two unrelated children from Kenya). The children's ages at the time of the interview ranged between three and 14 years old, with the mean of 8.6 and the median of nine. The ages of children at the time of adoption ranged between six weeks and eight years old, with the mean of 26.5 months and the median of 15 months. Ten of the 13 children were two years old or younger at the time of their adoption. This statistic is consistent with the U.S. Department of State data on internationally 
adopted children (2012). Nine of the 13 children (69\%) lived in orphanages prior to adoption, and four of the 13 children ( $31 \%$ ) came from foster families.

Three families adopted more than once over the years: one family had two separate adoptions from Russia (Alice), one family adopted a sibling group from Kazakhstan followed by another child from South Korea (Lilian), and one family adopted from Colombia, then from South Korea, and then again from South Korea at a later time (Melinda). In terms of ethnic and racial demographics, three families became transracial as a result of international adoption (Sandy, Lilian, and Casey), one family was transracial prior to the adoption (Melinda), and three families adopted children of the same race as them (Karen, Alice, and Judy).

As a rule, the questions were asked in the order that they appear on the interview protocol; however, on several occasions the participants' narratives flowed naturally into a discussion of another topic of interest for this study. In those cases, the participants were allowed to proceed and expand on that issue. The findings are presented in the order of questions asked by the researcher. Table 2 provides the summary of what participants discussed in response to each question. 
Table 2. Summary of participants' responses.

\begin{tabular}{|c|c|}
\hline Question & Participants' responses \\
\hline \multirow{3}{*}{$\begin{array}{l}\text { How did you come to a decision to adopt } \\
\text { a child from another country? }\end{array}$} & Decision to adopt \\
\hline & International versus domestic adoption \\
\hline & Choosing the country \\
\hline \multirow{5}{*}{$\begin{array}{l}\text { What was the adoptive process like for } \\
\text { you? }\end{array}$} & More than one adoption \\
\hline & Timeline \\
\hline & Emotions \\
\hline & Making meaning of the adoptive process \\
\hline & Unique challenges \\
\hline \multirow{7}{*}{$\begin{array}{l}\text { Please describe the first few months with } \\
\text { the newly adopted child. }\end{array}$} & Easy baby/Easy fit \\
\hline & Routine \\
\hline & Older siblings \\
\hline & Personality differences \\
\hline & Challenges \\
\hline & Communication/Language \\
\hline & Bonding process \\
\hline \multirow{3}{*}{$\begin{array}{l}\text { How did the child fit with your nuclear } \\
\text { family and the extended family? }\end{array}$} & Acceptance and support \\
\hline & Lack of understanding \\
\hline & Biological children \\
\hline \multirow{3}{*}{$\begin{array}{l}\text { Have you experienced any issues in } \\
\text { regard to your child's ethnic or racial } \\
\text { background? If so, please describe them. }\end{array}$} & Experiences of same-race families \\
\hline & Experiences of transracial families \\
\hline & Coping strategies \\
\hline \multirow{9}{*}{$\begin{array}{l}\text { What were the supports and other } \\
\text { resources available to you in your } \\
\text { adoption journey? }\end{array}$} & Other adoptive families \\
\hline & Technology \\
\hline & Extended family/Friends \\
\hline & Church community/Faith \\
\hline & Adoption agency/Case worker \\
\hline & Professional community \\
\hline & Giving back \\
\hline & Asking for help \\
\hline & Lack of support in a foreign country \\
\hline \multirow{7}{*}{$\begin{array}{l}\text { How can the services in the professional } \\
\text { community meet your needs better? }\end{array}$} & Follow-up/Post-placement support \\
\hline & Connecting parents to resources \\
\hline & Raising visibility \\
\hline & Understanding adoptive parents' experiences \\
\hline & Taking responsibility/Asking for help \\
\hline & Geographical advantage \\
\hline & Gratitude \\
\hline $\begin{array}{l}\text { What would be one sentence/word } \\
\text { summary that describes your entire } \\
\text { adoption journey? }\end{array}$ & $\begin{array}{l}\text { "Would do it again in a heartbeat." } \\
\text { "Unexpected." } \\
\text { "Blessed." } \\
\text { "Meant to be." } \\
\text { "Completely worth everything." }\end{array}$ \\
\hline
\end{tabular}




\begin{tabular}{|l|l|}
\hline & $\begin{array}{l}\text { "The most fun adventure I ever had." } \\
\text { "Adventure. Journey of faith." } \\
\text { "Heaven and hell. Both the best and the worst." } \\
\text { "A long traveled journey to get to the end of the } \\
\text { rainbow." }\end{array}$ \\
\hline
\end{tabular}

\section{How Did You Come to a Decision to Adopt a Child from Another Country?}

When asked about their decision to adopt a child from another country the families' responses reflected the decision-making process that was comprised of three components: the actual decision to adopt, choosing international adoption over domestic adoption, and choosing the country from which to adopt.

Decision to adopt. Four of the seven families interviewed for this study reported always wanting to adopt whether or not they could have biological children: "Adoption was always in my heart;" "Something that I wanted to do since I can ever remember;" "Always thought about adopting at some point." The other three families reported coming to a decision to adopt after exhausting other options of having a child: "So we just came to the conclusion that the end result is that we both wanted to be parents together and we didn't really care how that happened."

Overall, for six families that were interviewed adoption came as a second choice after attempting to have a biological child first: "We kind of thought that we would have biological children first and maybe adopt later [...] but we didn't end up having biological children, so we decided to start the adoption process." There was only one family among the seven participants that did not attempt to have biological children before proceeding with adoption: "Biological was never something I was interested in" (Casey). Thus, Casey's family narrative stands out from the rest:

I met my husband and on one of our dates he was like, "So before this goes any deeper, you should know, I just don’t have any desire for a biological family." He's like, "My heart's for adoption." And that's when I was like, "I should probably take him 
seriously." We were older, so we kind of knew what we wanted out of life, and to grow our family through adoption was just a natural thing for us.

Consistent with the existing literature on adoptive parents, the theme of loss permeates the narratives, whether it is losing a pregnancy, an infant child, or fertility (Pryor and Pettinelli, 2011; Shapiro, Shapiro \& Paret, 2001; Silverstein \& Kaplan, 1982). One family who experienced the loss of their infant son stated that "we decided that we are never going through that again and we were just going to try international adoption." Another family who had serious fertility issues after the birth of their first child considered other options for having a second child, including surrogacy, before deciding that "international adoption made the most sense for our family." Thus, for most families, the decision to adopt was a result of careful deliberation and thought.

International versus domestic adoption. The reasons for choosing international adoption over domestic adoption were consistent with the existing research on international adoptive families. The families interviewed for this study reported feeling "apprehensive" about the domestic adoption and being unwilling to "get into foster care system in this country." Two families reported hearing "troublesome stories" of domestic adoption scenarios in which the adopted child was taken back by biological parents. At least two families reported never considering domestic adoption because "international adoption was our best way to go." Among the cited reasons for not choosing domestic adoption were: a desire for a closed adoption ("We were interested in closed adoption at the time"), unwillingness to go through the U.S. foster system ("We didn't really want to get into the foster system here in our country, just not the greatest system"), a longer wait to adopt a child from the U.S. ("You can sign up with the 
adoption agencies here in our country but they would tell you sometimes there's like a five to ten year waiting list"), and psychological reasons:

After going through the loss of our son, domestic could be a lot more difficult, just a lot of ups and downs, and waiting to be chosen, and that type of thing... Any time you do anything like that there will be a certain amount of stress and heartache anyway. We felt like international was our best way to go.

International adoption appealed to the participants for the following reasons: permanency of placement ("You got the child and you kept the child"), goodness of fit ("Traveling internationally was kind of a part of our lives, something easy and familiar to us, so it seemed to make a lot of sense to adopt internationally for us.") and multicultural component, as reported by Casey (“Adoption to me was a neat concept. And of course, as a little girl I didn't understand the dynamics of adoption, but having other children from other countries in your family seemed very fun to me") and Melinda:

We really felt like international would be a good fit with us and what we desired our family to look like and culturally to feel like. We speak Spanish, we want to raise our kids to be bilingual; there are a number of cultural influences, so we just went international.

Choosing the country. The reasons for choosing the country from which to adopt varied greatly and reflected the families' values. Sandy, a mother who adopted from Guatemala, reported that the most important factors that they considered in their choice of a country were getting a child from a foster care system rather than an institution, and the geographical proximity to the U.S. A family that adopted from Russia stated that they chose this country because they wanted to have a child who looked like them and who would not "have to stand out 
being different" in the small town where they lived (Karen). Another family that adopted from Russia reported that they chose Russia for their "formulaic" and "cut and dry process," and because there was less wait than with other countries. Melinda, a mother who chose Colombia, reported that they wanted to adopt from a South American country because of her Hispanic heritage and a desire to raise children in a bilingual household (the parents spoke Spanish). Two families reported that they chose Kazakhstan because they felt some degree of connection to the country, whether it was from personal exposure ("So we've been to Kazakhstan before, fell in love with the country and Kazakh people.") or from hearing about it from friends:

We initially started working with Russia and then we started hearing that there was turmoil that we were having a lot of anxiety about, and meanwhile we had some friends who did some mission work in different baby houses in Kazakhstan, [...] and they said, "If there's an issue with Russia, would you consider Kazakhstan?"

Casey reported that although she did not have a preference from which country to adopt, her husband wanted to adopt from India until he went on a trip to Kenya: "While there, he visited orphanages, he actually met our daughter. She was two at the time. He always says that's when she adopted him. So he came home and switched everything up because now we had a kid." Thus, a serendipitous event led to a Kenyan adoption.

Three families that were interviewed went through the international adoption process twice. One family chose to go back to Russia to adopt the second time, and two families chose to adopt from South Korea after adopting their first children from Colombia and Kazakhstan, respectively. Both of these families reported that adoption from their original countries of choice became impossible due to policy changes, although one family stated that they would have adopted from Colombia again and the other family reported that they did not want to adopt from 
Kazakhstan the second time. In both instances, South Korea was chosen by the families for their well-oiled adoptive process and predictable timeline:

We were kind of emotionally spent, and we said, where in the world has there been the least amount of change in the international adoption? And the response was, "Well, that's easy, that's South Korea." And so we said, all right!

\section{What Was the Adoptive Process Like for You?}

There were differences and similarities that emerged in the families' narratives in response to this question. Since the participants adopted children from several different countries, the adoption policies of each country played an important role in their journey. These policies affected the length and the procedures of each adoption, and in turn, colored the parents' emotional experiences. Participants discussed their coping strategies and challenges during the adoptive process. Below are the findings on the adoptive experiences reported by the parents.

More than one adoption. Three families that were interviewed adopted children more than once, and in each case, the adoptive experience was different. A family that adopted from Russia twice reported that their second adoption process was easier and much faster: "I didn't even want to tell people we met how fast it was going." Two families that did their second adoption from a different country reported that each adoption process was different "like night and day."

Parents who adopted more than one child emphasized the benefits of including their older children in the adoptive process of the younger child: "So the boys were older and we were super excited, we really included them in the whole adoption process, we thought of it as an opportunity to understand adoption." Another family expressed a similar sentiment about including their older boys in their daughter's adoption: 
The nice thing about that is that we were able to bring them with us on that first trip, so it was kind of like a family vacation to Korea, and it was neat because they got to experience a whole other culture, they got to meet their sister, kind of see firsthand where she is coming from. And it was a great opportunity for them to experience adoption from an outside perspective, so a lot more questions about their stories came up during this process and we were able to have some really good conversations. So that was really cool. (Lilian)

Timeline. Depending on the adoption policies of the country, the timeline of each adoption was different. Some families described the length of their adoption journey as a "quickly turning process" and "super-fast roller coaster," and some reported that it was a "very, very long waiting process." One family stated that "in retrospect, it wasn't that long; it just feels longer when you're in it." One mother likened her adoptive experience to pregnancy: "It was almost like we were in that pregnancy stage emotionally and just waiting to hear what will become of it. [...] I feel like the timeline was almost like pregnancy, the preparation and the interviews."

Emotions. There was a vast range of emotions accompanying the adoptive process for the families that were interviewed. Overall, the prevailing theme in the narratives of the participants was anticipation. Among the most common reported emotions during the adoptive process were "exciting," "frustrating," "nerve-racking," "uncertain," and "painful." Different emotions were reported during different stages of the process.

One mother described her excitement when she was looking at databases of children available for adoption: "Then your mind starts running with it and get excited. It was probably a bad thing because we were getting more and more excited [...] and we just had to continue to 
wait." Several families reported feelings of uncertainty throughout the adoptive process: "You were just sort of hanging in the air a little bit."

There was a lot of positive emotion associated with getting a referral for a child. One mother described her reaction after learning that they were matched with a son:

It was very exciting. I was at work, my husband was at work, so I ran over, grabbed the pictures, and I took pictures with my phone and text messaged him the pictures so he could see, and of course at that point all of our coworkers knew what was going on at that moment of time, so they were all excited. So a lot of hustle and bustle basically. Undoubtedly, one of the biggest highlights in the participants' experiences was meeting the child for the first time. Two families that adopted children from Kazakhstan focused on this event at a greater detail due to going through a "blind referral process." Whereas the norm for most families was to receive a referral for a particular child followed by a subsequent meeting and eventually, adoption, the practice in Kazakhstan was to invite the family into the country first, and then present them with a child that was chosen for them. In both cases, the families reported not feeling "right" after meeting the children to whom they were introduced the first time: "We didn't feel like he was our son." Judy talked about her intuition after arriving to their destination in Kazakhstan: “This just doesn't feel right, maybe it's a mother's instinct, I'm not sure, but it just never felt like it was where we were meant to meet our son." For this family, the boy who was first introduced to them turned out to be too old to adopt, leading to misunderstanding: "We weren't allowed to adopt him even though they introduced us, so we were very confused." However, when this family saw another child who was introduced to them they felt an "instant connection:" 
We both looked at each other as we saw [our son] and said: “Oh, that's it, we're done." So it was very quick once we got there, every step felt right even though it was hurried, and frantic, and exciting, and nerve-racking. And emotional, extremely emotional. It was amazing.

Another family that adopted a sibling group from Kazakhstan reported a similar experience of not feeling like it was a good match with the children who were introduced to them:

And so we met with a director and we thought it was just a meet-and-greet kind of moment, and in the middle of this meeting all of a sudden they bring these two little boys in and these two boys immediately call us "mama" and "papa." I felt like I had just been punched in the gut because my reaction was, "These are not my children, something is wrong, I don't know what's going on, this is crazy, but these are not my kids, we have to figure this out." I felt like it would be really similar if I had been pregnant carrying a child, went to the hospital, gave birth, then they take the baby away, clean the baby up, all that kind of stuff, and they bring back a different baby. And I would've been like, yeah, that's not my kid. I don't know what you're doing with my kid but this one is not mine. So that was kind of a feeling that we both had... (Lilian)

In this case, the parents went through a "painful process" of trying to communicate to the orphanage officials that "something was wrong and this was not the right match" and "feeling like everybody is lying to us, can't trust anybody, we don't know what's going on." In the end they were introduced to two brothers with whom the parents felt an immediate bond: "We felt an instant connection with him, and for myself, after we had left meeting him, I couldn't stop 
smiling, I couldn't stop looking at his picture, so for us that felt like confirmation that these were our kids."

Depending on the country, some families could bring their child home immediately after meeting them and some could not. Three families that were interviewed reported that they had to make at least two trips to the country before the adoption was finalized. All three families uniformly agreed that having to leave their child behind was the hardest part of their adoption process: "It was really tough to leave him there and not know when you will be coming back. That was really the worst part."

Different emotions colored the moment of taking custody of the child and separating him or her from the previous caregivers. For one mother it was a very painful experience:

It was just heart wrenching. That was definitely the worst part because you feel like you're the one doing this, you want to love this child and take care of them, and you know that you just ripped her out of the arms of the only mom she's ever known, which is her foster mom.

For another mother the transition went rather smoothly: "I felt like I had a newborn for one night, that's it. [...] It literally took me maybe 24 hours to get his schedule and he was just incredible the whole time."

One family discussed how the experience of meeting their second child differed from meeting their first one:

It was even different when we went to see him. [First son] is like, ok, we're going to do this now, that's fine. [Second son] isn't like that. So it's in part his personality. So [first son] would be happy to see us and he would just go along, he played. [Second son] cried 
like the first hour we were there every time. A little bit more stressful, you know. (Alice)

The family that adopted two children from Kenya had a unique narrative about their adoptive process. Unlike other countries, Kenya did not have an international adoption program at the time; therefore, these parents did not go through an adoption agency. Rather, they were pioneers in a program that allowed potential parents to adopt an orphan after four months of fostering that child in Kenya. For Casey, four months turned to a year because of civil unrest that broke out in Kenya. Her husband had to return to work in the U.S. and the mother stayed behind with two children:

Looking back, I have fantastic memories of it... But at the time, I was freaking out. That was scary! I was by myself, and that can be depressing anyway. The other adoptive family, they left before their adoption was completed, and they went home. That was a huge loss for us, because they had really befriended us. We just really didn't know a lot of people, so a lot of loneliness, but it was also good. I had a lot of time with my kids without the interruptions of life, and that was probably really good for them. [...] So it was a lot of good concentrated time, but as far as emotionally, I was very lonely, and a lot of times, during the violence times, at night you were scared because you could hear. You know, we were in a guarded gated community. It was just that like, "what if?" sometimes was overwhelming.

This mother described her adjustment to the country, bonding with her children, and finding support in the community. She talked about the hurdles she had to overcome during that time as well. Overall, the adoptive process for this family was unlike any other family's experience with adoption. 
Making meaning of the adoptive process. Several families talked about making meaning of their adoptive process which allowed them to cope during that time. The common sentiment was accepting the negative experiences as part of the greater positive outcome: "You just have to bite the bullet and see the end of the rainbow"; "In the end, you gotta go through labor pain one way or another, right? So that was the labor pain." Two families reported that they relied on their faith to see the greater good that their experience brought them: "Because of our faith we feel like we can look at our story and see that there's a plan in there and that was the plan we didn't understand"; "My husband and I are both practicing Christians and so, eight steps that led up to this were very much meant to be."

Casey, the mother who adopted two unrelated children from Kenya, saw her adoptive process as a force that was both destructive and constructive at the same time: "We like to call it a train wreck. It was a train wreck. It was a great way to put it, because we wrecked their world and they wrecked our world, and then we all put ourselves back together."

Unique challenges. Two families reported unique challenges that threatened to jeopardize their adoptive process. According to Lilian, the youngest child they were adopting was exhibiting extreme behavioral problems during the mandatory bonding period in his birth country, including screaming, biting, and hitting. The parents reported having a very difficult time managing these behaviors: "We actually got very, very close to the point of saying that we couldn't handle finishing the adoption, which was really, really hard." In this case, calling home and talking to the social worker, friends and family helped the parents find hope, look at their experience from a different perspective, and successfully finalize the adoption.

Another family found out that they were pregnant while they were in the process of adopting from Kenya - a country that only allowed adoptions by couples who could not have 
children of their own. According to Casey, this pregnancy became another hurdle in their already difficult journey to adopt: "It was a really tough spot in our adoption. [...] We couldn't reveal our pregnancy because they really were looking for any reason to call this a failed adoption." She explained that in her child's country of origin, adoption by fertile couples was regarded with suspicion:

It was very hard for them to understand that we didn't have a different motive. We weren't looking for domestic servants, we weren't looking to sell children's body parts, you know, all those fears that are not born in a vacuum. It makes sense in their perspective, so why would you do this? It's so unheard of, especially in their country. Thus, the mother hid her pregnancy until the adoption was finalized and she arrived home with her children.

Several families reported facing challenges that were outside of their control, such as the countries going through adoption policy changes. In two cases, Guatemala and South Korea halted all adoption processes resulting in anxiety and "crazy angst" for the parents until the issues were resolved. In another case, Russia shut down international adoptions temporarily and the parents switched to another country from which they eventually adopted. Feelings of uncertainty dominated these families' narratives. As one mother put it, "We kind of struggled our way through it."

\section{Please Describe the First Few Months with the Newly Adopted Child.}

There were 11 finalized adoptions for the seven families that were interviewed resulting in the total of 13 adopted children. In response to this question, the parents were encouraged to describe their life as a family after each completed adoption, rather than adjusting to life with each individual child. The data analysis revealed that the child's age at the time of adoption 
played an important role in the post-adoptive adjustment period. For example, one family that adopted a young child likened their initial adjustment to bringing home a new baby:

It's just completely different but yet it's the same in a lot of ways, because it's all about change... So it was definitely having a baby and figuring out your life and I think that part is no different than any other experience.

Easy baby/Easy fit. Of the 13 children that were adopted by the participants, ten were under the age of two at the time of adoption. Overall, the families overwhelmingly reported that their process of adjustment to life with young children was very smooth: "It was a real honeymoon phase", "It seems like it was a very smooth process for us", "People asked us if we were going to do it again long time ago, and we were both, 'No, this one has gone way too good, way too smooth, and the odds of that happening again are slim to none." In eight instances the parents described their young children as a "happy baby", "extremely easy," "go with the flow kind of kid," and a "happy old soul." Several parents commented that their children fit right in with the family: "It was very easy to include him in life we already had"; "We are very fortunate with him, he'll do whatever you're doing"; "She fell very naturally into our family."

Routine. Three families discussed the importance of following the child's schedule and keeping transitions down to a minimum during that adjustment period:

We had to stick to his schedule as much as possible when we got home so that it wouldn't be too much of a change. We figured it would be enough of a change of environment that we would need to stick to a lunch schedule, breakfast, nap time, bed time, all of that. And he really was a creature of habit, too.

Older siblings. Three families who had older siblings at the time of adoption discussed the sibling's positive role in welcoming a new child to the family: "[Older brother] was very 
protective of him, like he was excited that he was getting a new brother: 'I'm going to do this, I'm going to teach him this.' He was pretty excited about it." Families also discussed how their new child's adjustment was facilitated by the older siblings:

Having the boys around was a huge help. I think that she would've had a harder time adjusting had it not been for the boys. Her dad and I would try to read her stories, play with her, nothing. But if the boys did it she would respond a little bit, and slowly and surely she opened up more. (Lilian)

The boys took like to her, she took like to them, I think that helped. She was just immediately drawn to them, like little kids playing together, and she found them entertaining, and they found her entertaining, so it was a very sweet thing. (Melinda) Personality differences. Families who adopted more than one child discussed differences in their children's personalities that affected the initial process of adjustment to the family: "Her adjustment has felt easier than their adjustment";

She came to us, she was supposed to do a visitation, and she was like, "No, I'm staying." She just kept saying, "My mommy," and she kept holding my hand. So she stayed and that was it for us. Then the little boy was scared to death of us. He wouldn't even look at us in our faces. [...] He was just that freaked out by us. (Casey)

Challenges. The few challenges that the parents reported in regard to adjusting to life with their young children during the first months was "emotional clinginess" and detachment. Melinda talked about her experience with the second daughter who appeared quiet and detached after they brought her home: 
"She is just kind of here, she is not excited... She was easy and it was a smooth transition with her because she just had no demands, she was just as happy to be held as she was on the floor with toys.

Another mother, Lilian, described her daughter's state of shock for the first two months after being separated from her foster mother in South Korea:

When we brought her home she would barely talk, she wouldn't play, and I wasn't so much a person to her as I was a security blanket. So if I was ever not within her sight she would freak out, and if I went to the bathroom she would just stand outside the door crying, waiting for me. That was emotionally hard, emotionally draining.

Sandy also commented on her daughter's initial separation anxiety: "If I would leave the family room she would cry and she would want to go with me, so for that first couple of weeks I probably carried her everywhere I went all the time.”

Communication/Language. All families adopted children from non-English speaking countries, and several families commented on the challenges the language barrier presented: "They would struggle trying to communicate;" "I think the language component for some of them [adopted children] has been more challenging than others";

He didn't understand us and we would get the funny looks from him, and he was trying really hard to put things together, but just that small language barrier made it difficult for us to find what was going on that he needed.

Bonding process. The families discussed bonding with their children after bringing them home. For most parents, the bonding process appeared to be smooth and heartwarming: 
I just feel like we're really lucky because they both just wanted us, and neither of them was over clingy, but they both just, ok, you're mom and dad, and what it means... It seems like it was a very smooth process for us (Alice);

"She definitely didn't have any issues with me or my husband, even going to immediate family [...] She just adapted so easily to the other people;" "It was pretty amazing to see how he changed throughout those weeks, just feeling comfortable and very much bonded by the time we left, so we were very grateful for that."

The parents who adopted two brothers from Kazakhstan, ages eight and four, discussed their challenges during the initial bonding process while they were still in the country: "[Younger son] was basically such a mess, he was acting out like crazy: he was screaming, he was biting, he was hitting..." According to the parents, these behaviors improved upon arrival to the U.S. after some time: "Our ability to care for him and deal with those behaviors was much easier and went much more smoothly once we were here because we were in a stable environment and we had our support system around us." Their mother, Lilian, described her struggle with adjusting to her new children after bringing them home:

That was definitely an area for me that was more of a challenge than I expected because throughout the whole process we had to take all these online classes and read all these books, and everything was basically about the attachment process for the children. There was hardly anything about the attachment process for the parents. So when I got back home with them, I went through a period of time, $[\ldots]$ there were six months where I felt like I was just wandering around in a daze and it was hard for me... My senses were overwhelmed, so that was a little bit of a hard adjustment for me. [...] I did not expect to feel that way at all. 
The family that adopted two children from Kenya had unique circumstances surrounding their adoption: the mother spent a year in Kenya fostering her children while their adoption was being processed. According to Sandy, the bonding process was facilitated by feelings of isolation during their time in the country:

We just really didn't know a lot of people, so a lot of loneliness, but it was also good. I had a lot of time with my kids without the interruptions of life, and that was probably really good for them. So it was a lot of good concentrated time. [...] We fell into a routine, and we found places we could walk and fun things to do. So we sort of started to be a family, just the three of us.

For this family, being away from familiar surroundings was a catalyst for bonding, so when they moved to the U.S., the children's adjustment to the new country went smoothly: "I think their adjustment was a lot easier because we were with them for a year, so we were family. So it's kind of like a family moving to another country, that adjustment for them was a lot smoother." However, the mother experienced reverse culture shock upon her return:

For me, it was hard. It was culture shock all over again. You come from where you are comfortable, living among people who don't have what you have, and you come back, and you're like, "We have so much." Sometimes that is a worse culture shock than being with people who don't have, and for the first couple of weeks, I didn't want to drive the car. We walked to the grocery store, we walked to the doctor's office. Because it was trying to hold on to, maybe? I don't know. The first time I walked to the grocery store, I couldn't shop, I couldn't finish. There was just too much stuff. And the kids were like, they were just... overwhelmed. The lights, and the stuff and... So that was, for all of us, the things that are here, what was such a culture shock for us. (Sandy) 


\section{How Did the Child Fit with Your Nuclear Family and the Extended Family?}

All families that were interviewed reported that the reaction of their extended families was mostly positive. Some parents talked about a lack of understanding by certain family members. Parents who had biological children also discussed the family dynamic that was unique to them.

Acceptance and support. In response to this question the parents discussed their extended families' and closest friends' reactions to their children. The unanimous agreement was that people who are closest to the families were largely accepting and supportive. As one mother put it, "Everybody loves him, they all want a little piece of him, everywhere he goes he is like a little superstar, and they love to be around him, he's been welcome in every circle."

Several families reported that their extended family, closest friends, and/or church community were an essential part of support after adoption. This support included bringing meals to their home, helping out with the children, and celebrating the adoption together. One mother talked about their extended church community involvement: "They brought us meals and they came and held kids and played with kids and really wrapped around us, as people would when you have a biological child." At least one family reported that initially there were some concerns and disagreements within the extended family about choosing international adoption; however, it has not been a problem since:

I think they all just sit a little bit in awe of him because he is such an important part of our family but has a different story, a story that we don't know a ton about in terms of lineage and that kind of thing, but for the most part though it has felt unconditional from the time they met him, so that's more than we could ask for... 
Lack of understanding. Despite overarching support from those around them, several families also reported some challenges in their interactions with other family members regarding their children. One mother stated that she becomes "sensitive" when she hears her nephews' remarks on family resemblance when her son is within the ear shot:

They still talk about, oh, you have Papa N.'s eyes or you're going to play baseball like Papa N., they say these things to one another, so when those things come up, those are the only times when I feel like, hey, he's right here too! It's the only time when I get a little bit more sensitive about that connection for him.

One mother discussed her struggle with educating family members who do not understand that talking about adoption with her children is normal: "So their love and acceptance of him included, why do you have to bring that up? That's the past, we're family, they're part of your family, we don't understand why you have to talk about it with them." To this mother it has presented challenges over the years:

Having to navigate that and do it in a non-combative way with our own family has been grueling. We had to grow in our own understanding, and our own maturity, and our own ability to extend grace to them for their lack of understanding and just know that it helps them to try to see that loving and accepting our children doesn't mean that you deny their past or that you're not able to talk to them about that. That it's okay to talk about hard things, it's okay to have these hard conversations but that has meant for me to have hard conversations with my own family. (Melinda)

Biological children. Three families had biological children in addition to the adopted children living with them. They discussed the dynamics between family members and the ways 
that they are making it work. One mother, Melinda, became pregnant shortly after adopting her son and soon found herself caring for two children who were 15 months apart:

It really was like having twins to some degree, I know it was not exactly like that [...] but they were very close in age, so part of how I handled it was very much treat them like twins in a sense of, we did all activities together, we did all play groups together... Another mother, Casey, told a story about their biological child who was struggling to fit in his family:

Actually, to be honest, our middle kid, our third, was struggling. Really struggling because our family promotes adoption pretty hard. We do it at churches, we do it at functions, and we do it with friends. We're always talking about it. Oddly enough, a bio kid can start to feel very left out. He was really struggling: "When are you going to adopt me?" He kept asking us that question, it was very interesting. So we sought out other families that have that dynamic - that mix of bio and adopted - and we talked to bio kids who were in adopted families, and the consensus was, "I wish I had someone to identify with that was traveling my journey." The ones who had that, yeah, there is something about having someone - and I think adopted kids feel that way, and we take that into account, which is why we like to do our adoptions in twos, because to have someone to identify with is really important. But you don't think about that with bio kids, because you're like, "Identify with me!" You know?

After careful deliberation this family made a decision to add another biological child to the family and reported that it was beneficial to all children because it opened doors to conversations about their births. 


\section{Have You Experienced Any Issues in Regard to Your Child's Ethnic or Racial Background? If so, Please Describe Them.}

There was a noticeable difference between the narratives of parents who adopted children of the same race as them and families who adopted children of a different race. Transracial families focused on race to a greater extent and were more likely to report difficult experiences: "That is such a loaded issue." Overall, the theme of likeness emerged from the narratives. Looking alike or not alike was mentioned by every family that was interviewed, regardless of the family composition.

Experiences of same-race families. In several instances same-race families brought up the child's resemblance to themselves or their family members: "It was uncanny, resemblance was amazing. [...] The pictures that we had initially, he looked just like my grandfather, you would've thought he was his son."

The advantages of looking similar were discussed: "We wanted the child to have an option to share their story... It is definitely his story to tell";

You know where we live [a small town], and we thought to ourselves that even though our child will always know they were adopted it would be nice if they didn't have to stand out as being different... We just thought that it would make things easier for them in the long run. (Alice)

The families also talked about how strangers perceive them: "With the boys who actually look like us, a lot of the time people are surprised that they are adopted"; “The strangers don't know that they are adopted"; "Now people do say to me, where did he get his nose, or he must look like your husband, and depending on the company I say, 'Yeah, he does look like my husband,' depends on the conversation." Overall, same-race families did not report any negative 
remarks from strangers due to strangers' inability to detect differences between the parents and the children.

A family who adopted two boys from Kazakhstan, ages four and eight, discussed their children's ethnic identity development six years after adoption. According to the parents, the older child has strong ties to his Russian identity whereas the younger child identifies as an American:

[Younger son] has not gone down that path a lot, calling himself a Russian, for him it's not much of an issue. And I don't know if that's because we got him when he was younger. You know, [older son] was eight when we got him, so maybe between four and eight you can create your identity who you are. His identity is more American whereas [older son] has four years of living in a Russian orphanage. (Lilian) Experiences of transracial families. The narratives of transracial families differed greatly in their experiences with ethnic and racial factors depending on the country of origin. The transracial families in this study consisted of three sets of parents who identified as Caucasian, and who adopted children of Hispanic, Asian, and African origin. Another set of parents identified themselves as Hispanic and Asian, and adopted children of Hispanic and Asian origins, respectively. For some transracial families, differences within the skin tones in the family were less detectable by others, leading to less intrusion by strangers:

People don't even know unless we tell them she is adopted. [...] Am I glad for her sake? Because I think yes, in this world it does make things a little bit easier for her. I don't mean to say I'm glad, I think it simply makes things easier for her. (Sandy, mother of a girl adopted from Guatemala) 
The awareness of how these families are perceived by others has manifested itself in other narratives as well, as is evident in Lilian's account:

We most stand out when we go someplace where there is a majority of Asians. If we're in a mixed crowd, I don’t feel like anybody notices. [...] You just have a sense of like, she looks more like them than she does like us and that feels awkward.

Overall, the families who are visibly different from each other focused on reactions from strangers, comments from their children's peers, and the children's search for identity. Melinda, a mother of Hispanic descent who adopted children of Hispanic and Asian origin with her husband who is Asian discussed the strangers' reactions when their family is out in public: "We cause a lot of confusion generally and that's okay, we find a lot of humor in that." Another mother, Casey, who has African-American and Caucasian children living in the household reported that she is frequently asked whether she does day care or foster care. Both families noted that they receive different reactions from different racial groups: "So we have a Caucasian community and we have an Asian community that we will interact with, so we will get predictably varying comments from those different populations." Sometimes these comments can be unsolicited and unwelcome:

I've been stopped in the Korean community and asked how much Korean I am teaching the girls and that they really need to be learning Korean. And I'm just like, 'I'm doing my best, I'm really doing my best.' But you stranger coming up to me and telling me that I need to teach my kids Korean is really not helpful. [...] I mean, you're a total stranger, why would you walk up to me and say that? (Melinda)

Other examples included strangers walking up and asking questions about adoption: 
With the girls it's not uncommon for someone to just say, 'Oh, where did you adopt them from?' I mean, no conversation, 'How old were they when you adopted them?' That happened recently and the girl came up, and [the daughter] looked at me and said, 'How did she know we were adopted?' (Melinda)

In some cases, the reactions from strangers can be hostile, as was Casey's experience during a shopping trip with her son:

There seems to be a huge acceptance of the fact that they are adopted from Africa, but had they been adopted from here, there seems to be a tension there, sometimes with the African-American community. [...] It's "we take care of our own; you don't need to take care of ours." Whereas people have a concept that all of Africa is poor, and it's a very altruistic thing that you've done. [...] On a few occasions, we've been out, and we've had people of the African-American race just glare at us, just really bear down on us. And [my son] notices it. I went to them and I'm just like, “This is a problem because you're making him feel really bad. You think he chose to be in my family, he didn't." [...] She just looked at me and walked away.

Despite this particular negative experience, the mother reported that most of the time overall stranger remarks are favorable.

Peer remarks by other children were also considered problematic by transracial families. Two families reported that their children have heard such statements as "she must not be your real mommy" and "that can't be your brother because you're not the same color" from their peers. 
Some parents talked about their children's search for racial identity. Sandy described the time when her daughter, who is Hispanic, began asking questions about her hair being darker and different from her mother's:

I remember at the time she was about three going through that. I actually had my hair dyed. It was quite a bit darker so that she could identify with me, and it worked, like she seemed to stop asking questions about that at the time.

Casey, the mother of two children from Kenya who are not biologically related to each other, reported that there are different ways that the racial issues affect her children:

Our son has had issues with his race from the very beginning. Just part of it is just who he is, part of it is that he is very dark. So within his own colors he stands out. Within our family culture he stands out. She [daughter] doesn't mind standing out, [...] she is used to people looking at her. He feels that everybody who looks at him is critical.

She added that as her daughter got older she expressed a desire to look Caucasian (or "peach," in her words):

For [my daughter] it's really just starting to show up now that she is a young woman. [...] She said, "I wish I was peach." She never said that before. She's just always kind of fallen into... whatever, she's a very laid back person. But I think the dynamic is starting to challenge her.

Coping strategies. The parents who reported challenges with racial and ethnic factors also offered an insight into their coping with these experiences. According to one mother, racial issues are an important discussion in their household: "We feel like education and being willing to have those conversations in our home and with our extended family, and even with our friends, is important to do." Another mother expressed the same opinion: "I feel like education 
is key." Both of these families believed that it is important to be open in their discussion of race in order to increase their children's level of comfort with it: "Dealing with the questions, and the inquiries, and the comments when they are made, and being selective about that is something that we are all learning to do"; "We bring it up a lot, just so that it's a really normal safe topic for him." Both families talked about emotion-focused coping and using these experiences as an opportunity to grow and feel empowered:

So just being able to not easily be offended, I think that's one thing we're trying to help our kids, and even for ourselves to not easily be offended. But again, using it as an opportunity to learn and not just to teach, so, what can I learn from this situation; You want to acknowledge the pain but you don't want to put it on a child to be a victim. Yes, in truth you are a victim of your circumstances but you can choose to take that out and be a stronger person. So we acknowledge the pain, and we talk about how it's wrong for people to say that, but how we can be change agents.... You can choose to respond and to be an educator. (Melinda)

The importance of being responsive to the children's needs and validating their feelings was emphasized: "You have to acknowledge their pain, you can't dismiss it. ... Because that's a real pain and you want your kids to always feel okay to come to you;" "I wanted him to know I'm always in his corner."

The family that adopted children from Kenya discussed their efforts to facilitate positive racial identity development for their children, including looking for African American role models in the community and mentoring a group of African American children weekly in their house. This family also reported maintaining close ties with the friends they made in Kenya and making trips to Kenya. The mother, Sandy, discussed incorporating Kenyan culture into their 
daily lives: "We have Kenyan dinners, and we have Kenyan dresses that we wear, just to really celebrate their culture." In fact, all families that were interviewed for this study reported maintaining some degree of connection with the child's birth culture. Some of the activities that the families engaged in included reading books, looking at pictures and mementos from the child's birth country; participating in a Spanish-speaking play group; cooking ethnic meals at home as well as going to ethnic markets and restaurants; and attending events at a local Russian church. Several families reported planning trips to the birth country when their children get older. Most parents emphasized the importance of being open about adoption with their children and encouraging discussions about their cultural background: "By all means, we have been very upfront with her from the very beginning, even when we first brought her home. Some of the kid story books I read were regarding adoption, any kind of adoption.”

\section{What Were the Supports and Other Resources Available to You in Your Adoption}

\section{Journey?}

Overall, the families reported having adequate support during their adoption journey: “We just felt like we were supported enough that we knew we weren't alone and if we needed to reach out there were definitely people that were able to give us an advice or at least an ear." The parents discussed different systems of support they found helpful, including other adoptive families, online social networks, agency and case workers, extended family and friends, church and faith, and professional community. Some parents reported a greater need for support whereas other parents felt like what they had was sufficient enough. The importance of reaching out for help and giving back to the community was emphasized.

Other adoptive families. Most families agreed that one of the most vital support systems came from getting connected to the adoptive community and forming relationships with 
other adoptive families: “... other adoptive families; you find them and then you have that instant bond, so friendships are formed..." This support was essential during the entire adoption journey:

Emotionally we had a great support group, we were with a whole group of families, there were about six of us, so we were all waiting together during that time. [...] We would cry on each other's shoulders when we thought somebody was coming at a certain time and they wouldn't come, and we celebrated when somebody got a referral, we all met each other at the airport when we would come back, so it was just really great... (Melinda)

Several families reported that these relationships lasted through the years: "We are still friends with several other families that we met while we were in Guatemala"; "We are still in touch with those couples now 15 years later, our kids know each other."

Technology. Among some of the activities in which the participants engaged with other adoptive families were forming parent support groups, getting together for playdates, and connecting to online adoption groups on social network websites. At least half of the families considered technology and social networking helpful in their adoption journey: "Facebook has been awesome. Adoption groups on Facebook will do an event here and there..."

One mother shared that she started a blog in order to keep her friends and family updated on the adoption process:

It was important for me as we were going through it to be able to share without necessarily sharing all the true worries. You know, you worry about things and you want people to know what's going on but you don't tell them your deepest darkest fears or 
whatever. I created a blog and I went through the process with everybody without being necessarily face-to-face personal. (Sandy)

Extended family/Friends. More than half of the families that were interviewed mentioned relying on their extended family for support: "I couldn't have done it without them. My really close family [...] just came around our kids. They felt very accepted and the grandparents came over and helped [...], and my aunt came and stayed with them." Support from friends and community was also greatly appreciated by the parents: "Living in a small town that we do, we have a lot of support from a lot of people. Just when we came home with [our son], some signs were put up: 'Welcome Home!"

Church community/Faith. Church community and relying on belief system was an essential part of the support system for at least half of the families that were interviewed: "Our church family $[\ldots]$ they are our friends and they are very much our surrogate family"; "And it really was our faith that helped us deal with all that."

Adoption agency/Case worker. According to some parents who were interviewed, adoption agencies were a good source of support: "The agency did a great job educating us." It was also important for families to have a good relationship with their case worker:

You really see a difference between a case worker that gets to know you as a family, really is passionate about this process and wants you to win, wants you to succeed, versus somebody that is doing an eight to five job.

Professional community. The families discussed resources that were available to them in the professional community. Among the services that the families utilized were speech therapy, specialized medical appointments, counseling, and various assessments. In addition to that, one mother reported that enrolling her son in daycare was "the smartest thing we ever did" 
because it allowed him to socialize and adjust after life at the orphanage. Four families reported no need for ongoing professional interventions after adoption, and three families reported utilizing various post-placement supports in the form of counseling and/or other treatments.

Giving back. Some families discussed the importance of giving back to the community and being active in supporting other adoptive families: "So we were almost sort of pioneers within our church and became champions for adopted families, and we have a group that just wraps around adopted families. That's their mission";

Our case worker would contact us and say, "We got another family getting ready to go through international adoption, we wanted to let them talk to you, is that ok?" We're like, "Sure, we'd be happy to share our experiences and pay it forward." (Lilian) Asking for help. One mother discussed the importance of asking for help from their social support system during the adoption journey:

It was that element of really letting them know what we need and I think a lot of times that's hard to do because it's a very hard process. [...] I think a larger challenge is that the adoptive community needs to admit that we need help. And there is no shame in asking for help.

Lack of support in a foreign country. Two families that had to spend an extensive period of time in a foreign country reported a lack of support while they were there: "When you are in country, for the most part there was not a lot of support." In both instances the families felt isolated: "We just really didn't know a lot of people, so a lot of loneliness..."; "It was hard to be in a country where you really can't communicate well with anybody." 


\section{How Can the Services in the Professional Community Meet Your Needs Better?}

Overall, the responses of the participants were based on the needs they had and whether these needs were met. Families who commented on the absence of any special needs were less likely to indicate that the services in the professional community are lacking: "Because we didn't encounter any big problems we didn't seek out a lot of other help";

There just weren't any red flags where we needed to connect her with additional type of that service. Had there been any, by all means, we would have sought it and you know, done whatever we needed to. But there really just wasn't a need.

On the contrary, families who experienced challenges expressed a greater need for support from the professional community:

We had seasons of challenges with the kids and working through, we decided to seek counseling. We've decided to seek some therapies and interventions, and it's hard to say that sometimes, it's hard to be real about that and say, we've got a beautiful family and everything looks great, and we clean up really well, but day to day it's really hard and we need support.

Follow-up/Post-placement support. Most participants commented on the lack of follow-up and post-placement support after the adoption was finalized:

I think that what is lacking is the follow-up. [...] Because you do all this study before, but it's irrelevant. It's like going to college. In college you study all the basics and you think, 'When am I ever going to use these things?' Then as a teacher you get into a classroom and you're just like, 'I wasn't prepared for this.' You feel a little bit like that. The feeling of having studied but not being prepared resonated with another mother as well: 
So that was definitely an area for me that was more of a challenge than I expected because throughout the whole process we had to take all these online classes and read all these books, and everything was basically about the attachment process for the children. There was hardly anything about the attachment process for the parents... [...] I think for myself, I just didn't expect to need that kind of help and support. (Lilian)

The definition of post-placement support was different for each family. For one mother, it was having someone check on them periodically: "I really think it would be so helpful if you had your own caseworker that called you three weeks into it and said, 'How are you? Are you struggling with temper tantrums?' Another mother wished to belong to a formal group that met on a regular basis: "I think what is missing is a more formalized connection to a group. [...] You kind of have to create it on your own or find it on your own." For another mother it was a more responsive medical community: “I don't feel like they are listening to me. We've listed the same concerns for the last couple of years, and I feel like we get the same answer every time, and the problem is never solved."

Melinda emphasized the importance of acceptance of post-placement support by the families:

But post-placement, that's a whole other area of support I think needs to really... It's growing but families need to be embracing that, and being prepared that you're going to need post-placement support, and it's not just going to be the first year, it may be 5 years, it may be for many-many years, and that can look like therapy, that can look like a variety of interventions, and there's nothing shameful about that.

Connecting parents to resources. Three families that were interviewed commented on the lack of connection between the parents and the resources available to them. These parents 
agreed that there are many resources that parents are not aware of: "There are resources available but many adoptive families are not taking the advantage of those resources." One mother, Melinda, discussed her shock when the director of her adoption agency complained about the lack of resources on adoption:

She said, "There's so little being published, like books for the public on adoption," and I'm thinking in my head, these books coming out, I can't keep up with the books coming out! [...] I feel like there's so much hope, so much material that these adoptive parents don't realize is there. But she said, "We're running out of resources on a resource table," and I was like, "Are you serious? Are you kidding me?"

Raising visibility. Two families stated that the professional community should take more initiative in reaching out to the parents and being aware that "there is a market, the various needs exist." According to one mother, more outreach by the professional community and easier access to services would be highly beneficial for adoptive families:

I think that getting that information in parents' hands makes a difference. I think that professionally, again, just being there to say, 'We're a resource.' [...] That's how the professional community can really serve adopted parents. If there were somebody that you could pick up the phone and say, 'Here is what I'm struggling with, who can I talk to?' and they connected you, that would be huge.

Understanding adoptive parents' experiences. Naturally, the participants expressed a need for professionals who know and understand their struggles: "If you are coming from a perspective of not understanding the adoption experience, it's probably not going to be as effective as I would like it to be." One mother discussed her preference for professionals who have first-hand knowledge of adoption: "One of the counselors we're working with now, and she 
is amazing, is an adult adoptee herself. And I can't tell you the level of credibility with my kids that created and the level of trust."

Taking responsibility/Asking for help. Several families that were interviewed commented on having to be proactive in order to find help: "The families have to step up; I think all the opportunities for us were there, so we still have to take initiative to move into them." The families recognized that they had to take responsibility for their own welfare: "There were a lot of times when we had to go help create those resources." A part of that responsibility included the families' acceptance that they may need outside help: "There is an element of professional community being visible but I think a larger challenge that the adoptive community needs to admit is that we need help. And there is no shame asking for help."

Geographical advantage. All families that were interviewed resided either in a large urban area or within an hour drive from a large city, like Pittsburgh, Pennsylvania, Baltimore, Maryland, or Washington, D.C. Therefore, services in the professional community were easily accessible to all families that participated in this study. One mother commented on the advantage that the geographical location offered their family:

We are in a great place, that's why we should have gazillion resources, but I wonder about people in other parts of the country that don't have so many adoptive or even foster families in their community or the resources that are available to them. (Melinda)

Gratitude. Three families stated that their needs have been met by the services available to them, and expressed appreciation for that: "I'm so glad that we had all the support, and the resources, and the people that we had... I feel very fortunate to have had the experience we did have." 


\section{What Would Be One Sentence/Word Summary that Describes Your Entire Adoption}

Journey?

The overall experience was reported to be highly satisfying for all families. Two families stated that they "would do it again in a heartbeat." One mother commented that it was "Unexpected." Other words that the families used to describe their adoption journey were "Blessed," "Meant to be," and "Completely worth everything." Some participants saw their experience as an adventure: "Crazy, fun, and I loved it. You have to be crazy to take on a task like this but it was the most fun adventure I ever had;" "A long traveled journey to get to the end of the rainbow;" "Adventure. Journey of faith." One father stated that this experience was "Heaven and hell. Both the best and the worst. Cringe at doing it again but we would do it in a heartbeat."

\section{Is There Anything Else that You Feel Is Important to Mention?}

Although there was no specific question about making meaning of the adoptive experience, the concluding question was open-ended, allowing families to add anything they felt was important to share. Several participants used that as an opportunity to reflect on their adoption journey and discussed the meaning it brought to their lives.

\section{He was supposed to be here.}

...he has this cyst, and he's been through 2 surgeries now and he has to go through another one. [...] I think about what would've happened to him if he would've been there because I don't know if anyone would've taken care of him the way he needed to be taken care of. I just don't think they would've had the resources to look after him the way that he needed to do it. Sometimes I just think that he was supposed to be here with us. (Alice, mother of two children adopted from Russia) 


\section{This is bigger than me.}

It's been better than I could've imagined. I mean, it's hard but I feel like... I used to say that I wanted adventure in my life, and I thought that adventure would be traveling the world and experiencing cultures... [...] and the amazing thing is that selfish desire, which is really a selfish desire, just an answer that I didn't have to go anywhere. I have been around the globe but really I feel like I built my family by bringing these children into my life. The opportunity to be their mom and to experience life with them, and it's been harder and yet more joyful than I could've ever imagined. And so God has taken that self-centered, youthful desire, all about me, and transformed it into what I'm getting to experience with my family [...] and it's because of adoption... (Melinda, mother of three children adopted from Colombia and South Korea)

\section{You can never prepare for it.}

The way our family has become so multicultural, it was just kind of unexpected, but you know, it's good things that are unexpected, bad things that are unexpected, painful things, happy things, you know, just there's a lot of things that you experience that you can never prepare for... The best preparation is just to know you cannot be prepared. It's a little bit like facing just being a parent in general - I could read a hundred parenting books, I'm never going to be prepared to be a parent, just have to do it. (Lilian, mother of three children adopted from Kazakhstan and South Korea)

\section{A most amazing experience to watch.}

I think that adoption is one of the hardest and best things that you can choose to do with your life. Like, it is not the pretty picture that maybe a bio kid is. But it is a most amazing experience to watch. These people come to you, and you don't realize until 
later, how empty their eyes are. And as you look at pictures as they grow and they become part of your family, all of the sudden, you're like, 'He looks just like me!' And the light in their eyes changes, and the freedom in their spirit changes, and you get to be a part of that. And so with struggles comes this amazing life experience. [...] And I think people have said so many times, like 'How could you love a kid that's not your own?'

But when you adopt, that child is every bit your own, and the adoption experience is just as amazing as the birth experience, and for some of us, we prefer the adoption experience. (Casey, mother of two children adopted from Kenya) 


\section{CHAPTER 4}

\section{Discussion}

The purpose of this study was to examine the narratives of American parents who adopted children from other countries in an attempt to understand their experiences and their current needs. The existing literature in this field has indicated that adoptive families utilize clinical services at a higher rate than biological families; however, mental health professionals often lack expertise on issues that are unique to these families (Adoption Institute, 2010). Therefore, this study assessed the needs of parents who adopted children from other countries in order to provide qualitative data that can inform clinicians who work with adoptive families. The research questions posed by the study were the following: (a) How is the process of international adoption experienced by the adoptive parents; (b) Are there common themes associated with psychological adjustment for parents who adopted children from overseas, and if there are, what are these themes; and (c) What are the needs of families with children adopted from overseas? The data was collected via semi-structured interviews with seven participants. Qualitative inquiry was chosen as the most suitable methodology for this study because it allows exploring and understanding this issue on a more complex, detailed level (Creswell, 2013). Specifically, thematic analysis of family narratives was used to examine the data and provide an insight on the participants' experiences with international adoption.

Overall, this study made a substantial contribution to the existing literature on experiences of adoptive parents and their needs. It not only confirmed and expanded previous findings on parental satisfaction with adoption, transracial issues, and parental adjustment, but also gave voice to adoptive parents through a self-reported assessment of their needs. It has been widely documented that adoptive families are three times more likely to seek clinical services 
than birth families, and among them, families with children from other countries have the highest utilization of supportive services (Adoption Institute, 2010). This study was the first to illuminate the specific resources that are lacking in the community for these families and how helping professionals can address this deficiency. Although the qualitative data collected in this research can be found useful by professionals in various fields, it is of most importance to mental health professionals who work with adoptive families.

As a whole, demographic information about the participants recruited for this study is consistent with the description of adoptive parents in the existing literature - predominantly white, generally older, married, college-educated, and financially secure (Hellerstedt et al., 2008). The children that they adopted represented a range of countries and ethnic backgrounds, were mostly younger at the time of adoption, and in most cases had a history of institutionalization. This demographic information supports the findings of Hellerstedt et al. about the younger age and early institution history of many adoptees from other countries (2008). As such, the families recruited for this study were a rather representative sample of the international adoption community. This, undoubtedly, is a strength of this research as it makes the data more generalizable.

One of the most notable themes that emerged through the thematic analysis of the participants' stories is a high degree of satisfaction with the adoption outcome and having no regret about the adoptive experience. This theme was evident in the summaries provided by the families at the end of the interview: "Completely worth everything," "Meant to be," and "Would do it again in a heartbeat." These findings are consistent with the previous research that shows that for over $90 \%$ of families, adoption remains a highly positive experience and brings special fulfillment to the parents (Adoption Institute, 2010; Shapiro et al., 2001). In fact, the general 
sentiment among the interviewees was that they would not hesitate to go through the experience of adoption again, even knowing about the hurdles in advance. This finding was reported in the previous literature as well (Adoption Institute, 2010) and implies a high degree of resilience among adoptive families. For that reason, it is recommended that mental health professionals adopt a strength-based approach when working with these families and focus on empowerment.

Other notable findings are discussed under each domain that was presented to the participants, namely, decision to adopt, adoptive process, the first few months with the child, fit with the extended family, racial/ethnic issues, supports and resources, and assessment of needs.

\section{Decision to Adopt}

As illustrated in Table 2, the participants' narratives on the decision-making process consisted of three components - making a decision to adopt, choosing international adoption over domestic adoption, and choosing the country from which to adopt. Regarding a decision to adopt, all families excluding one reported that adoption came as a second choice after attempting to have biological children. This is consistent with the previous works of Young (2012) and Hogbacka (2008), and it also supports the idea that fertility issues serve as a major motivating factor for adoption. The theme of loss was evident in the families' early narratives, corroborating the findings of Silverstein and Kaplan (1982), Shapiro et al. (2001), and Pryor and Pettinelli (2011). Therefore, one of the recommendations for mental health professionals who work with adoptive families is to assess for unresolved grief issues in therapy before proceeding with interventions.

The reasons for adopting a child from another country were consistent with prior research findings as well (Hogbacka, 2008; Pryor and Pettinelli, 2011; Shapiro et al., 2001). The participants cited the permanency of placement, more certainty in the adoption outcome, shorter 
wait for a child, unwillingness to get involved with the U.S. foster care system, and a perceived fit with the family composition. Regarding the choice of a country from which to adopt, the parents based it on their value system, familiarity with the country, and convenience of the adoptive process. Thus, the reasons that the participants discussed varied greatly among the families and included geography, racial composition, language, child care system, and personal connection to the country. It also appears that the participants were open to considering other options when external circumstances interfered with the country of their first choice. Overall, these findings are highly consistent with what has been previously described in the literature and provide a comprehensive view of the motives of parents who adopt from overseas.

To summarize, the decision to adopt a child from another country was by no means lighthearted. The narratives of the participants demonstrated careful preparation, determination, and commitment to the process of international adoption. Most parents who were interviewed had a history of significant loss and heartache before they chose to proceed with international adoption. Although every family had their own reasons for selecting a country from which to adopt, their choices reflected the value system of each family. Therefore, psychologists who provide interventions for these families must make an effort to work from the perspective of the families' values and be mindful of their history of grief and loss.

\section{Adoptive Process}

When discussing the adoptive process, the narratives of the participants were largely influenced by adoption policies of the sending country. In that regard, the accounts of families that adopted from different countries were highly divergent; however, numerous commonalities emerged when the narratives were examined from an emotional viewpoint. Parents who adopted more than once commented on how different their experiences were with each adoption. 
Naturally, these differences were magnified if the subsequent children came from other countries. For these parents, the consecutive adoptions became an opportunity to involve older siblings in the adoptive process and as a result, provide a teaching moment about their own adoption journey.

Most parents commented on the timeline of their adoptive process, specifically, their perception of how fast or slow it was going. An interesting parallel was drawn by one mother who compared the adoptive process to pregnancy, including the timeline and the emotions that accompanied both. Overall, emotional experiences became a focal point of the participants' accounts of their adoptive process. The description of the adoption journey as an "emotional roller coaster" has been widely documented before (Adoption Institute, 2010), and was evident in this study as well. The emotions were influenced by different stages of the adoptive process and ranged from excitement, to frustration, to uncertainty, to anxiety. The general theme that captured the emotional experiences during the adoptive process was anticipation.

Separate themes emerged for subgroups of parents who adopted under similar circumstances. Thus, the families who had to make more than one trip to the country uniformly agreed that leaving the child behind after meeting him or her for the first time was the hardest part of their adoptive process. One mother reported that the worst part was separating her child from the only caregiver her daughter knew - the foster mother. Although for some parents the transition went rather smoothly, for others it elicited a lot of emotional upheaval. The thematic analysis revealed that the parents made meaning during that time by the use of emotion-focused coping.

One of the advantages of using qualitative methodology for this study was an opportunity to examine unique narratives and to give voice to parents whose experiences did not conform to 
the group. For one family, it was an experience of being introduced to prospective adoptees who did not feel like they were their children. This feeling, and the subsequent sense of meeting the children that were meant to be theirs, was a novel finding that has not been reported in the literature reviewed for this research. An in-depth case study is needed to draw conclusions about the factors that contributed to this family's unexpected emotional experience. Similarly, another family's account of fostering their children during the civil unrest in a foreign country was an exceptional finding. Exploring unique narratives is one of the reasons why the qualitative design chosen for this study was the most appropriate method to study parental experiences with international adoption.

To summarize, the adoptive journeys of parents interviewed for this study were similar and dissimilar in several ways. Clearly, the adoptive policies of the sending countries played an influential role on how the parents experienced the process. This was evident in the timeline reported by the participants and the unique challenges that some of them described. However, despite the differences, it was the emotional component of the adoptive process that made the participants' experiences universal. Anticipating a child, whether through adoption or a pregnancy, is a highly emotive experience, and there was a vast range of emotions captured in the narratives of parents. The parents coped by making positive meaning of their adoptive experiences and in some cases, relying on their faith. For mental health professionals, these findings signify the importance of incorporating emotion-based work in therapy and assessing for potential psychological trauma. Additionally, discussing the adoptive process and processing their emotions is highly recommended for parents who seek counseling. 


\section{The First Few Months with the Child}

The period of adjustment to new life with an adopted child is a crucial time for forming attachment and solidifying the bond. Poor attachment between a parent and a child has been shown to correlate with higher parental stress and dissatisfaction with adoption (Welsh et al., 2007). Goodness of fit, defined as a match between parental expectations and the child's characteristics, has been suggested to play an important role in mutual attachment and adoption satisfaction (Tirella et al., 2012; Viana \& Welsh, 2010). Therefore, the author chose to focus on the first few months of the adjustment period in order to gain a deeper understanding of the emerging bond.

As mentioned previously, ten out of 13 children adopted by the participants were ages two or younger at the time of adoption. Consistent with the existing knowledge (Adoption Institute, 2010; van Londen et al., 2007), younger age undoubtedly served as a protective factor for adoptive families, as most parents of babies agreed that their integration into the family was overwhelmingly positive. The babies that these parents adopted were described as "extremely easy", "happy baby", and "good sleeper, good eater," which contributed to the smooth adjustment. The majority of parents agreed that the bonding process between them and their new children came easily during the first few months, although personality differences influenced the adjustment as well.

This is a highly encouraging finding, since the literature on attachment emphasizes the deleterious effects of early institutionalization and its role in the child's capacity to attach (Barth et al., 2005; Juffer, Bakermans-Kranenburg, \& van IJzendoorn, 2005; Shapiro, Shapiro \& Paret, 2010; van Londen et al., 2007). Several parents commented on emotional clinginess and detachment manifested by their young children after coming home. It must be noted, however, 
that these reactions indicate the child's attempt to cope with the new environment and do not predict long-lasting issues with attachment. In order to draw conclusions regarding this phenomenon, a thorough assessment of the child's early history and attachment style must be conducted. This can be one of the directions for future research.

Although most parents reported a smooth and easy bonding process during the first few months, one family that was interviewed found it more challenging. In this case, the risk factors described in the previous literature were present, such as older age at the time of adoption, male gender, and a history of institutionalization (Adoption Institute, 2010; Hawk \& McCall, 2010; Stams, Juffer, \& van IJzendoorn, 2002; van Londen et al., 2007; Welsh et al., 2007). The brothers that this family adopted were ages four and eight at the time of adoption and exhibited many externalizing behaviors during the initial adjustment process while still in their birth country. At one point, managing these behaviors became so difficult for the parents that they considered discontinuing the adoptive process. Despite this family's initial struggles, however, the parents persevered and there was significant improvement over time. Additionally, the mother also reported difficulties with her own adjustment period for the first six months after adoption that, in her own words, felt similar to postpartum depression. It is recommended that future research studies focus on examining post-adoptive mood changes in adoptive parents and investigate whether these changes are equivalent to postpartum mood changes in birth parents.

There were several strategies that some parents found helpful during an initial adjustment period, including following a routine and enlisting help of older siblings. One of the challenges that the families reported initially was a difficulty communicating due to the language barrier. This was not a long-standing issue, however, and many families found humor in their early attempts to communicate. 
Overall, the first few months presented both challenges and a sense of fulfillment for the parents. It was reassuring to find that for most families the initial post-adoptive adjustment period was uneventful and facilitated a positive bonding experience. The narratives of the participants confirmed the existing knowledge that it is generally easier for younger children to integrate into the family; however, personality characteristics contribute to that adjustment as well. Having older siblings and following a routine facilitated positive adjustment, and the language-related issues were found to be short-lived. One mother raised an important concern about a post-adoptive emotional state that resembles postpartum depression. More studies are needed to determine the degree in which post-adoptive adjustment period affects the parents' mood. It is important for mental health professionals to recognize the first several months as a crucial time for forming a bond between adoptive parents and their children. Therefore, one of the obvious clinical implications is that psychologists should utilize therapeutic interventions that facilitate secure attachment during the initial months. In addition to that, parents may benefit from seeking speech and occupational therapy, establishing a routine, and getting help from their existing social support system.

\section{Fit with the Extended Family}

Receiving support from the extended family has been found to be a protective factor in previous research (Tirella et al., 2012). Therefore, this researcher was interested to learn about the fit of the adopted child with extended family members with the purpose of assessing the parents' existing support system. The thematic analysis revealed that despite occasional lack of understanding by some family members, all parents commented on the acceptance and support that their extended families and friends provided them. 
Some parents discussed the dynamic between their biological children and adopted children. One mother's narrative in particular was thought-provoking. She described the struggle of her biological child to fit in with their family because they heavily promoted adoption. According to her, this child found it difficult to identify with other family members, including his biological parents. One of the clinical implications of this finding is that mental health professionals must consider the adjustment of all members of the family unit rather than just the dynamic between adopted children and their parents. As this case illustrates, the needs of biological children can sometimes be overlooked, and the entire family may be affected as a result. Although examination of the needs of biological children within an adoptive family unit is beyond the scope of this research, this example serves as an important highlight for future inquiries.

\section{Racial/Ethnic Issues}

As anticipated, the experiences of same-race families and transracial families were highly divergent. Same-race families generally denied any difficulties related to the child's ethnic or racial background, whereas transracial families described it as a "loaded issue." Same-race families were more likely to comment on their adopted child's resemblance to themselves or other family members and reported the strangers' inability to detect that their child is not biological. Transracial families, on the other hand, described different reactions from strangers, which they generally perceived as insensitive and invasive. Visibility of transracial families leading to unsolicited outsider remarks has been discussed in the previous literature, and this phenomenon was confirmed by the current study as well (Sutter \& Ballard, 2009).

Overall, parents of children of a different racial phenotype acknowledged the racial dynamics that exist in this country and were aware of the importance of instilling a positive 
racial identity in their children. In order to do that, the parents utilized various strategies, including open discussions, education, framing negative experiences as an opportunity to grow, acknowledging their children's pain, and emphasizing empowerment. Among the specific identity-affirming activities that the families engaged in were discussing their children's heritage while looking at books and photographs, cooking ethnic foods, wearing ethnic clothes, attending cultural events in the community, looking for role models for their children, and planning trips to the country of the child's birth. This corroborates the findings by previous researchers who reported that most adoptive parents are sensitive to cultural socialization issues and are involved in promoting a positive racial identity in their children (Lee et al., 2006).

In summary, issues stemming from the differences in ethnic and racial backgrounds within the adoptive family are an indispensable part of the adoptive experience. To their advantage, the parents interviewed for this study were aware about the importance of acknowledging the child's heritage and engaged in various activities that support a healthy racial and ethnic identity. Additionally, transracial families were highly sensitive about their visibility in public and the racial bias that exists in the society. Similar to parents described by Lee et al. (2006), the participants in this study were determined to teach their children healthy coping by encouraging open discussions about racism and discrimination, as well as promoting the child's ethnic knowledge, pride, values, and behaviors.

As Hellerstedt et al. have found, 97\% of adoptive families identified as White/Caucasian prior to adoption, and $88 \%$ of these families became transracial after adoption (2008). In this sample, four out of seven families were transracial. Due to unique multicultural issues that all adoptive families face, cultural sensitivity and competence in dealing with transracial adoptive issues is a must for professionals. It is imperative that psychologists continuously work on 
expanding their self-awareness, explore potential biases, and receive multicultural competence training. Additionally, consultation and supervision should be routinely utilized by mental health professionals who work with these families.

\section{Supports and Resources}

The parents interviewed for this study demonstrated a remarkable degree of resilience and resourcefulness during their adoption journey. The literature on international adoption commonly focuses on problematic aspects, which may lead to a skewed perception of the adoptive process as arduous and unrewarding. Although it is necessary to illuminate the struggles, it is also important to present a balanced view of the adoptive experience. Therefore, the participants were given an opportunity to discuss their strengths and the systems of support they had utilized during the adoption journey.

Connecting with other adoptive families, undoubtedly, was one of the most important assets for the participants. Several parents noted that these relationships lasted through the years and continue to be a source of support to them and their children to this day. Similarly, reaching out to the extended family, friends, and the church community has been found to constitute a major source of social support for the participants. Some families also reported that their adoption agency or their case worker were particularly helpful during their adoption journey.

To summarize, the importance of a social support system cannot be underestimated. It is a major protective factor for adoptive families that leads to a better post-adoptive adjustment (Adoption Institute, 2010; Tirella et al., 2012). As such, it has valuable clinical implications. Although the participants reported getting help from the professional community, such as speech therapy, specialized medical appointments, counseling, and various assessments, their main source of support came from people around them. Thus, therapists must be aware that 
professional services are not the first resource to which these families should be directed. It is recommended to assess their existing social support system and facilitate the connection to the adoptive community, church community, and to family and friends, depending on the preference of the family. Providing clinical services without establishing an adequate social support system is likely to produce only limited success with adoptive families. Psychologists must be aware that it is difficult for some parents to ask for help; therefore, community outreach is recommended.

Several families noted that while they were in their child's birth country, there was almost no support available for them. The difficulties that the families experienced abroad were exacerbated by the language barrier and the dependency on others for guidance. Although it is impossible to control the circumstances in a foreign country, therapists can prepare families for potential hurdles by providing psychoeducation and researching referrals outside of the country.

One mother emphasized the importance of being prepared and sharing her story with other families as a cautionary tale in order to "pay it forward." In fact, giving back to the adoptive community by volunteering, educating, and offering assistance to other families has been reported to be an important value for several families. Mental health professionals can use this information to encourage adoptive families to be more involved in volunteering. In addition to offering some intrinsic reward, giving back to the community helps foster connections with other families and strengthens the social support system.

Additionally, it appears that technology has become indispensable in serving the needs of the adoptive families and connecting them to resources. From blogging, to social networking, to researching information online, the parents who were interviewed for this study relied greatly on modern technological advances. This finding has significant implications for mental health 
professionals. According to the data reviewed by Lannin and Scott, the use of social networking sites has been steadily increasing among the adult population over the recent years; however, the majority of established psychologists do not have an online presence (2014). Parents who adopt children from other countries appear to be well-informed consumers of the digital world, and are likely to research the resources, including mental health services, online. Thus, it is vital for therapists to establish a bridge that can connect these families to needed resources through the internet.

\section{Assessment of Needs and Recommendations}

The participants offered invaluable advice for the professional community regarding the services they need. Clearly, adoption journey does not end after bringing the child home, and some adoptive families may need additional support for years to come. Overall, the needs of families in this study varied greatly, and parents who experienced more challenges with their adoption were more likely to indicate that the professional services are lacking. These findings are of great importance to not only counselors and psychologists, but to occupational therapists, speech therapists, social workers, and other professionals working with adoptive families.

One of the top requests for the professional community was formalized follow-up and post-placement support. According to the participants, this could take a form of regular home visits from a case worker, weekly or monthly support group meetings, and regular medical checkups. For psychologists in particular, offering an official support group that gathers on a regular basis is recommended.

The participants also indicated that although some resources exist, there is not a good connection between parents and these resources. As discussed previously, it is vital for the professional community to increase visibility and reach out to adoptive families. Technology, 
including blogging and professional social networking, can serve as a tool for outreach, advertising, and providing adoptive families with information. Mental health professionals can also participate in tabling events and formal gatherings organized by adoption agencies in order to increase their presence in the adoptive community.

The parents emphasized the benefit of working with counselors or social workers who understand their adoption journey, whether it comes from first-hand experience or having expertise in this field. According to one mother, finding a therapist who was an adult adoptee herself created a remarkable level of credibility and trust with her adopted children due to their perception that she "gets it." Regardless of first-hand experience with adoption, mental health professionals can improve their rapport with adoptive families by manifesting a genuine interest in adoptive issues, seeking additional training, and continuing to educate themselves on this topic.

The participants also acknowledged that they have a responsibility to ask for help when they need it. Often, the pressure to be seen as a perfect family is high on the parents, and seeking services from the professional community is perceived with a lot of stigma. Therefore, normalizing and validating difficult experiences is an important task when working with these families.

Lastly, many participants expressed gratitude about the professional help they received throughout their adoption journey and some parents commented on the advantages that their geographical location offers them. As it has been noted before, all families that were interviewed lived either in a large metropolitan area or within an hour drive of a larger city. Therefore, it is important to keep in mind that the professional services were easily accessible to them, and this finding cannot be generalized to families who live in more rural areas. The 
parents' appreciation for, and satisfaction with the existing services was an encouraging finding, however.

\section{Strengths and Limitations}

This study utilized a qualitative design that has an exploratory nature. The strength of this design is that it allows one to collect rich qualitative data that yields in-depth understanding of the research question. The data obtained in this research not only expanded the existing knowledge of the experiences of adoptive parents but also illuminated the unique narratives that have never been examined before. However, a limitation of any qualitative design is the lack of generalizability. Consumers of this research must keep that in mind when drawing inferences from the data.

The snowball technique that was used to recruit the participants provided a convenience sample of seven families. This is a rather robust group size for a qualitative analysis; however, due to the fact that several participants knew each other it is reasonable to assume that the families who were interviewed would gravitate toward each other because of similar values. As a result, this may have produced a highly homogeneous sample. On the other hand, this limitation may not be very meaningful because demographic information collected from the participants shows that they possess characteristics that represent adoptive parents in general. It can be argued that collectively, adoptive parents are a rather homogeneous group, and the sample used in this study is consistent with the general description of adoptive parents.

Geography presents both a strength and a limitation in this study. As mentioned previously, the participants were recruited from two locations - the Greater Pittsburgh Area and the greater area of District of Columbia and Baltimore. This allowed to obtain rather diverse perspectives on adoptive experiences and made the narratives richer as a result. On the other 
hand, the sample did not include perspectives of those who are raising adopted children on the West Coast, Midwest, or more rural areas. Therefore, the needs of more rural families have not been addressed in this study.

Due to the fact that the data for this study was collected and analyzed by a single investigator, researcher bias is a potential limitation as well. In order to address that, the researcher utilized a bracketing technique in which she disclosed information about her background and the nature of her interest in this study. To ensure trustworthiness of the study, she also provided the participants with the copy of the transcripts for member checking. Additionally, she carefully monitored her personal reactions to the parents' narratives and sought consultation when needed.

\section{Future Directions}

Despite a recent decline in international adoptions, there are thousands of families in the U.S. who are raising children adopted from overseas. Parenting is a lifelong journey, and this study provided only a glimpse into the struggles and triumphs of adoptive parents. More comprehensive research on parental experiences with adoption is needed as numerous unanswered questions remain.

One of the future directions for research is conducting more comparative studies between experiences of adoptive and birth parents. An important issue about an emotional state that was perceived as equivalent to postpartum depression was raised by a mother who struggled with post-adoptive adjustment. More research is needed to explore parental adjustment after adoption and to determine how similar and dissimilar these experiences are to parenting biological children. 
One of the focal points of this research was assessing the needs of adoptive families. Although the participants' responses provided an excellent overview of what could be helpful to them, very little is known about experiences of rural families who do not have access to services. Likewise, parents who adopted children with special needs have not been adequately represented in this study. It is recommended that future studies investigate issues presented by a more diverse sample of parents.

Finally, this research can be further expanded by developing empirically-supported therapeutic interventions that mental health professionals can use in their work with adoptive families. The impetus for this study was to gain understanding of the parents' experiences and to assess their needs. Overall, this thematic analysis provided solid answers to the research questions while generating numerous other inquiries. Therefore, in order to expand current findings, it is recommended that future research studies focus on establishing the efficacy of therapeutic interventions for adoptive families. This knowledge will benefit the parents of children adopted from overseas and helping professionals alike. 


\section{References}

Barth, R. P., Crea, T. M., John, K., Thoburn, J., \& Quinton, D. (2005). Beyond attachment theory and therapy: Towards sensitive and evidence-based interventions with foster and adoptive families in distress. Child and Family Social Work, 10, 257-268. doi: 10.1111/j.1365-2206.2005.00380.x

Braun, V. \& Clarke, V. (2006). Using thematic analysis in psychology. Qualitative Research in Psychology, 3 (2), 77-101.

Clandinin, D. J. \& Connelly, F. M. (2000). Narrative inquiry: Experience and story in qualitative research. San Francisco, CA: John Wiley \& Sons, Inc.

CNN Wire Staff (2010, August 1). Russian boy in U.S. adoption case back in orphanage, attorney says. CNN. Retrieved from http://edition.cnn.com/2010/WORLD/europe/07/30/us.russia.adoption/index.html

CNN Staff (2012, December 29). Russia's Putin signs anti-U.S. adoption bill. CNN. Retrieved from http://edition.cnn.com/2012/12/28/world/europe/russia-us-adoptions/index.html

Creswell, J.W. (2013). Qualitative Inquiry and research design: Choosing among five approaches ( $3^{\text {rd }}$ ed). Los Angeles, CA: Sage Publications, Inc.

Evan B. Donaldson Adoption Institute (2010). Keeping the promise: The critical need for postadoption services to enable children and families to succeed (Policy and Practice Perspective). Retrieved from http://adoptioninstitute.org/old/publications/2010_10_20_KeepingThePromise.pdf

Friedlander, M. L., Larney, L. C., Skau, M., Hotaling, M., Cutting, M., \& Schwam, M. (2000). Bicultural identification: Experiences of internationally adopted children and their 
parents. Journal of Counseling Psychology, 47(2), 187-198. doi: 10.1037//0022-

0167.47.2.187

Harf, A., Skandrani, S., Radjack, R., Sibeoni, J., Moro, M. R. \& Revah-Levy, A. (2013). First parent-child meetings in international adoptions: A qualitative study. PLoS ONE, 8(9), 18. doi: 10.1371/journal.pone.0075300

Hawk, B. \& McCall, R. B. (2010). CBCL behavior problems of post-institutionalized international adoptees. Clinical Child and Family Psychology Review, 13, 199-211. doi: 10.1007/s10567-010-0068-X

Hellerstedt, W. L., Madsen, N. J., Gunnar, M. R., Grotevant, H. D., Lee, R. M. \& Johnson, D. E. (2008). The International Adoption Project: Population-based surveillance of Minnesota parents who adopted children internationally. Maternal and Child Health Journal, 12, 162-171. doi: 10.1007/s10995-007-0237-9

Hogbacka, R. (2008). The quest for a child of one's own: Parents, markets and transnational adoption. Journal of Comparative Family Studies, 39(3), 311-330.

Juffer, F., Bakermans-Kranenburg, M. J., \& van IJzendoorn, M. H. (2005). The importance of parenting in the development of disorganized attachment: Evidence from a prevention study in adoptive families. Journal of Child Psychology and Psychiatry, 46(3), 263-274. doi: 10.1111/j.1469-7610.2004.00353.x

Josselson, R. (2011). Narrative research: Constructing, deconstructing, and reconstructing story. In F. Wertz, K. Charmaz, L. M. McMullen, R. Josselson, R. Anderson, \& E. McSpadden (Eds.), Five ways of doing qualitative analysis: Phenomenological psychology, grounded theory, discourse analysis, narrative research, and intuitive inquiry (pp.224-242). New York, NY: The Guilford Press. 
Kvale, S. \& Brinkmann, S. (2009). Inter Views: Learning the craft of qualitative research interviewing. Los Angeles: Sage.

Lannin, D. G. \& Scott, N. A. (2014). Best practices for an online world. Retrieved from http://www.apa.org/monitor/2014/02/ce-corner.aspx

Lee, R. M., Grotevant, H. D., Hellerstedt, W. L., Gunnar, M. R. \& The Minnesota International Adoption Project Team (2006). Cultural socialization in families with internationally adopted children. Journal of Family Psychology, 20(4), 571-580. doi: 10.1037/08933200.20.4.571

Levy-Shiff, R., Zoran, N. \& Shulman, S. (1997). International and domestic adoption: Child, parents, and family adjustment. International Journal of Behavioral Development, 20(1), 109-129.

McGuinness, T. M., Ryan, R. \& Robinson, C. B. (2005). Protective influences of families for children adopted from the former Soviet Union. Journal of Nursing Scholarship, 37(3), 216-221.

Pryor, C. \& Pettinelli, J. D. (2011). A narrative inquiry of international adoption stories. Journal of Ethnographic and Qualitative Research, 6, 45-61.

Seidman, I. (2006). Interviewing as qualitative research: A guide for researchers in education and the social sciences ( $3^{\text {rd }}$ ed). New York: Teachers College Press.

Shapiro, V., Shapiro, J., \& Paret, I. (2001). International adoption and the formation of new family attachments. Smith College Studies in Social Work, 71 (3), 389-418. doi: $10.1080 / 00377310109517637$

Silverstein, D. N., \& Kaplan, S. (1982). Lifelong issues in adoption. Retrieved from http://library.adoption.com/articles/lifelong-issues-in-adoption.html 
Stams, G., Juffer, F., \& van IJzendoorn, M. H. (2002). Maternal sensitivity, infant attachment, and temperament in early childhood predict adjustment in middle childhood: The case of adopted children and their biologically unrelated parents. Developmental Psychology, 38(5), 806-821. doi: 10.1037//0012-1649.38.5.806

Steele, M., Hodges, J., Kaniuk, J., \& Steele, H. (2010). Mental representation and change: Developing attachment relationships in an adoption context. Psychoanalytic Inquiry, 30, 25-40. doi: 10.1080/07351690903200135

Sutter, E. A. \& Ballard, R. L. (2009). "How much did you pay for her?": Decision-making criteria underlying adoptive parents' responses to inappropriate remarks. Journal of Family Communication, 9, 107-125. doi: 10.1080/15267430902773253

Tirella, L. G., Tickle-Degnen, L., Miller, L. C. \& Bedell, G. (2012). Parent strategies for addressing the needs of their newly adopted child. Physical and Occupational Therapy in Pediatrics, 32(1), 97-110. doi: 10.3109/01942638.2011.610434

Twohey, M. (2013, September 9). The child exchange: A Reuters investigation. Retrieved from http://www.reuters.com/investigates/adoption/\#article/part1

United States Department of State, Office of Children's Issues (2013). FY 2012 Annual Report on Intercountry Adoption. Retrieved from http://adoption.state.gov/content/pdf/fy2012_annual_report.pdf

Van Londen, W. M., Juffer, F., \& van IJzendoorn, M. H. (2007). Attachment, cognitive, and motor development in adopted children: Short-term outcomes after international adoption. Journal of Pediatric Psychology, 32(10), 1249-1258. doi: 10.1093/jpepsy/jsmo62 
Viana, A. G. \& Welsh, J. A. (2010). Correlates and predictors of parenting stress among internationally adopting mothers: A longitudinal investigation. International Journal of Behavioral Development, 34(4), 363-373. doi: 10.1177/0165025409339403

Voigt \& Brown (2013, September 17). International adoptions in decline as number of orphans grows. CNN World. Retrieved from http://www.cnn.com/2013/09/16/world/international-adoption-main-story-decline/

Welsh, J. A., Viana, A. G., Petrill, S. A., \& Mathias, M. D. (2007). Interventions for internationally adopted children and families: A review of the literature. Child and Adolescent Social Work Journal, 24(3), 285-311. doi: 10.1007/s10560-007-0085-x

Wimmer, J. S., Vonk, M. E., \& Reeves, P. M. (2010). Adoptive mothers' perceptions of reactive attachment disorder therapy and its impact on family functioning. Clinical Social Work Journal, 38, 120-131. doi: 10.1007/s10615-009-0245-x

Young, A. (2012). Choosing intercountry adoption: An Australian study of the motivations and attitudes of intending and recent adoptive parents. Australian Journal of Social Issues, $47(2), 221-241$.

Zhang, D. (2010). Intercountry adoption: Clashing colors of a family portrait. UCLA Asian Pacific American Law Journal, 15, 160-186. 


\section{APPENDIX}

\section{Demographic Questionnaire}

\section{$\underline{\text { About you }}$}

1. Name

2. Age

3. Race

4. Relationship Status (single, partnered, married)

5. Highest level of education

6. Occupation

7. Income Level (circle one) \$20,000 - 39,000

$$
\begin{aligned}
& \$ 40,000-59,000 \\
& \$ 60,000-79,000 \\
& \$ 80,000-99,000 \\
& \$ 100,000+
\end{aligned}
$$

8. Do you have any biological children? If yes, how many?

\section{About your adopted child(ren)}

9. Name

10. Age

11. Race

12. Age at the time of adoption

13. Country from which your child was adopted

14. The year when the adoption was finalized 